\title{
Empirical Study Of Tube Wave Suppression For Single Well Seismic Imaging
}

Phillip B. West

David M. Weinberg

James R. Fincke

May 2002

Idaho National Engineering and Environmental Laboratory Bechtel BWXT Idaho, LLC 


\title{
Empirical Study Of Tube Wave Suppression For Single Well Seismic Imaging
}

Phillip B. West

David M. Weinberg

James R. Fincke

May 2002

Idaho National Engineering and Environmental Laboratory Idaho Falls, Idaho 83415

\author{
Prepared for the \\ U.S. Department of Energy \\ Natural Gas and Oil Partnership \\ National Petroleum Technology Office \\ and the Office of Fossil Energy \\ under DOE Idaho Operations Office \\ Contract DE-AC07-99ID13727
}




\begin{abstract}
This report addresses the Idaho National Engineering and Environmental Laboratory's portion of a collaborative effort with Lawrence Berkeley National Laboratory and Sandia National Laboratories on a borehole seismic project called Single Well Seismic Imaging. The INEEL's role was to design, fabricate, deploy, and test a number of passive devices to suppress the energy within the borehole. This energy is generally known as tube waves. Heretofore, tube waves precluded acquisition of meaningful single-well seismic data. This report addresses the INEEL tests, theories, observations, and test results.
\end{abstract}




\section{FOREWORD}

The Single Well Seismic Imaging (SWSI) project was initiated in March 1996 as part of the, then, Borehole Geophysics Forum, which later became the Diagnostics and Imaging Forum under the direction of the Natural Gas and Oil Technology Partnership administered by the Department of Energy's National Petroleum Technology Office (NPTO), now located in Tulsa, Oklahoma.

Starting in 1995, the petroleum industry challenged itself and the Department of Energy with building a number of borehole seismic systems to improve subsurface imaging. To address the industry challenge, the Idaho National Engineering and Environmental Laboratory (INEEL), Lawrence Berkeley National Laboratory, and Sandia National Laboratories collaborated on the Single Well Seismic Imaging project, which uses an acoustic source and receiver in the same borehole. A petroleum industry group, the Saltflank Imaging Consortium, co-sponsored this project by providing funds and in-kind donations. Lawrence Berkeley National Laboratory was the lead lab for this project and will issue a final project report in the near future.

The three laboratories devised a collaboration scheme that would offer the best division of labor based on laboratory capabilities. Sandia National Laboratories' representative, Dr. David Aldrich, performed the bulk of the seismic modeling, Dr. Ernie Majer of Berkeley, undertook the data acquisition and processing tasks. The INEEL's Phillip West, under the direction of Dr. Dave Weinberg, took on the task of building a device that would inhibit, or at least suppress, the energy that traveled within the wellbore. This report addresses the INEEL portion of the work.

The INEEL work was done under a Cooperative Research and Development Agreement (CRADA), Number 98-CR-01, details of the INEEL work can only be disclosed to outside parties with the written permission of both CRADA partners for a period of five years from the CRADA expiration date $(10-18-00)$. 


\section{ACKNOWLEDGMENTS}

The authors wish to express special thanks to Alex Crawley and Bob Lemmon of the U.S. Department of Energy, Office of Fossil Energy's National Petroleum Technology Office for their support in this project. Additional thanks go to Dr. Jack Cole (University of Arkansas), Dr. Sen Chen (ExxonMobil), and Don Howlett (formerly of Texaco) for their advice and help in putting this project together. In addition, we thank the various companies that made up the Saltflank Imaging Consortium for their assistance and support in field operations. We also acknowledge the support and help of Larry Walters, Harold Merry, and Mike Sheen of Geospace Engineering Resources. 


\section{CONTENTS}

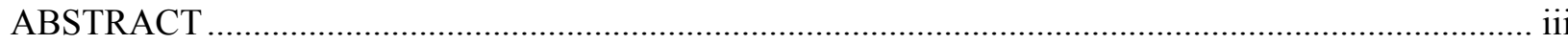

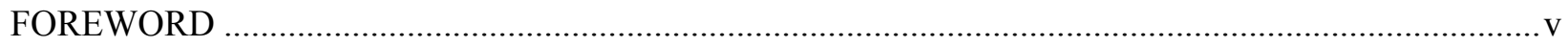

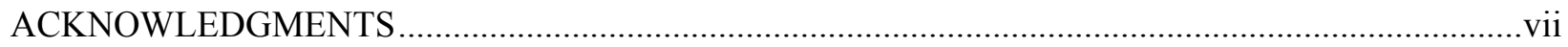

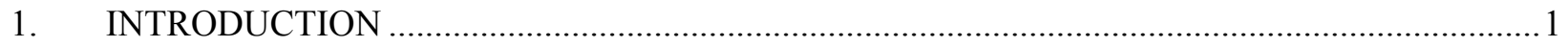

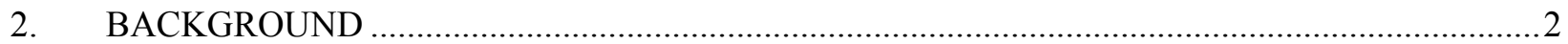

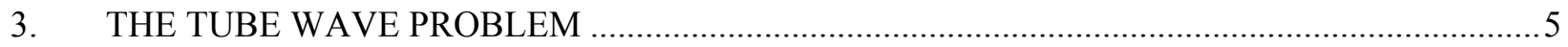

3.1 What is a Tube Wave-A Mechanical Perspective..............................................................

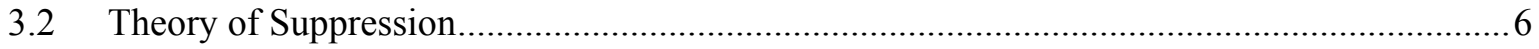

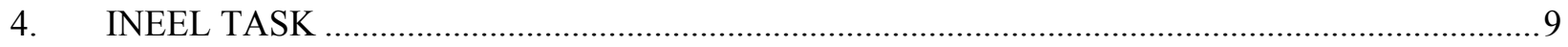

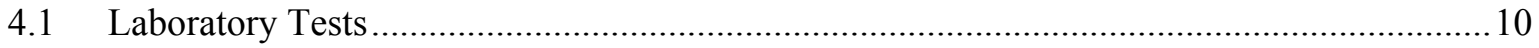

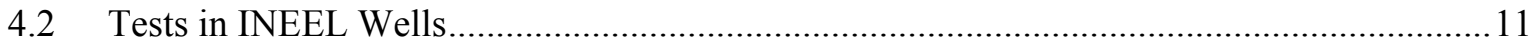

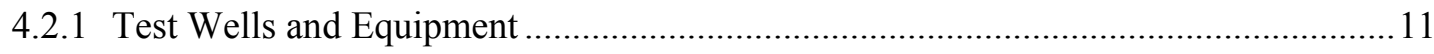

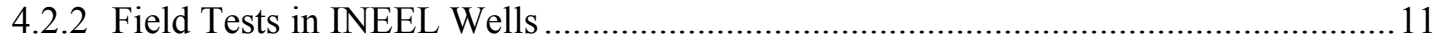

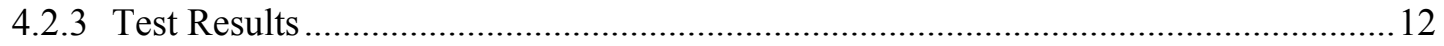

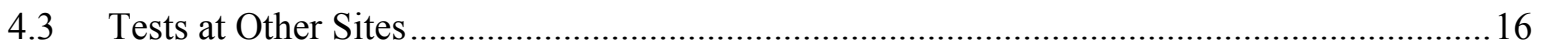

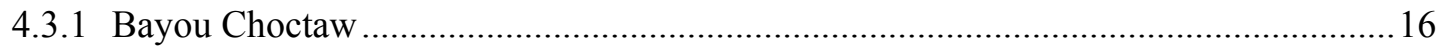

4.3.2 Richmond and Bakersfield, California ..................................................................... 17

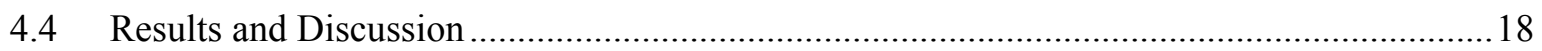

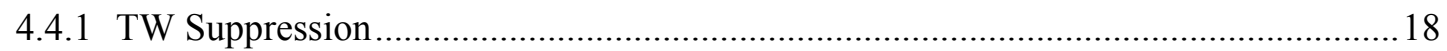

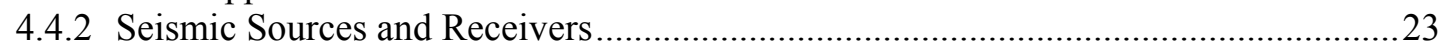

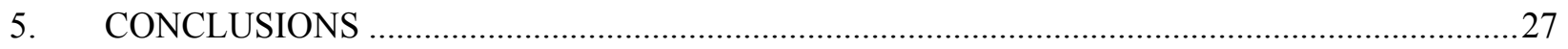

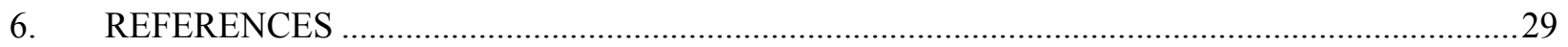




\section{FIGURES}

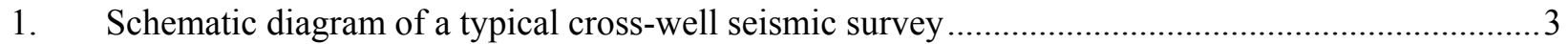

2. Cross-section of a portion of the Bayou Choctaw oil field in southern Louisiana ...........................4

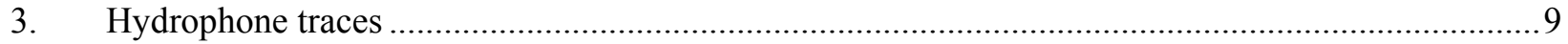

4. Laboratory apparatus for quick screening of tube-wave suppression ......................................... 10

5. Output traces of pressure transducers on either side of central flange .......................................11

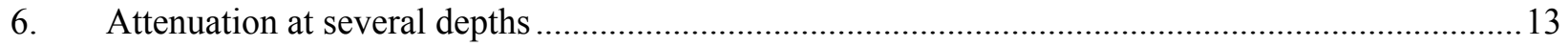

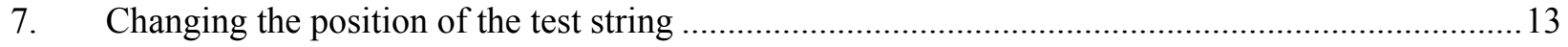

8. Dominant frequencies recorded by hydrophones with a purged suppressor................................. 14

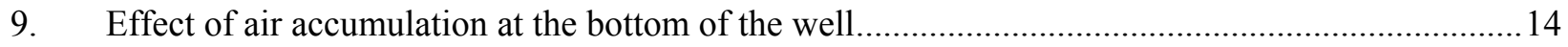

10. Large magnitudes of energy can be dispositioned without actually reducing amplitude of the initial part of a signal

11. The effect of TWs (suppressed and unsuppressed) on a clamped geophone .................................15

12. Tube-wave suppressor being deployed at Lost Hills oil field near Bakersfield, CA ....................... 18

13. Inflated, but not tight, bladder suppresses hydrophone signal from piezoelectric source ...............19

14. Both sets of $\mathrm{x}, \mathrm{y}, \mathrm{z}$ geophone signals are suppressed by a bladder ..............................................20

15. Both pairs of hydrophone traces are from tests using a $1 \mathrm{ft}$ long, 2 in. diameter steel tube with

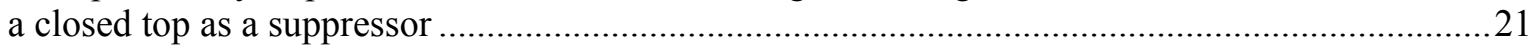

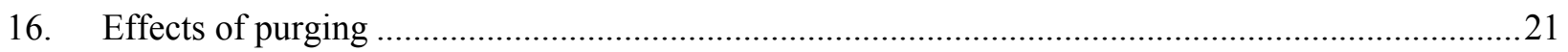

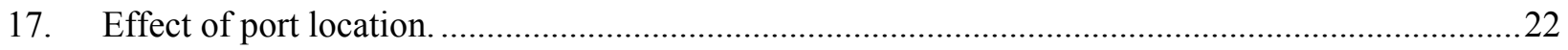

18. Tri-axial recordings of an unclamped wireline geophone module with no suppressor and of internally clamped wireline geophone module with no suppressor.

19. Tri-axial recordings of a clamped wireline geophone module with suppressor and of internally-clamped wireline geophone module without suppressor.

20. Tri-axial recordings of a clamped wireline geophone module with no suppressor and of internally clamped wireline geophone module with a suppressor above the module and below the source ....25

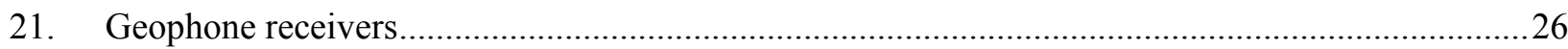

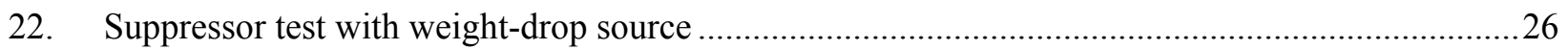




\section{Empirical Study of Tube Wave Suppression For Single Well Seismic Imaging \\ 1. INTRODUCTION}

This report describes the Idaho National Engineering and Environmental Laboratory's portion of the Single Well Seismic Imaging (SWSI) project. This project is a collaboration with Lawrence Berkeley National Laboratory (LBNL) and Sandia National Laboratories (SNL) to build a borehole seismic system to improve subsurface imaging. The goal was to develop a system with an acoustic source and receiver in the same borehole. The Idaho National Engineering and Environmental Laboratory's (INEEL) task was to build a device that would inhibit, or at least suppress, the energy that traveled within the wellbore. The bulk of the seismic modeling was performed at SNL; data acquisition and processing were performed at LBNL. The Saltflank Imaging Consortium, a petroleum industry group, provided funds and in-kind donations. LBNL was the lead lab for this project and will issue the final project report.

The INEEL work was done under a Cooperative Research and Development Agreement (CRADA), Number 98-CR-01; details of the INEEL work can only be disclosed to outside parties with the written permission of both CRADA partners for a period of five years from the CRADA expiration date $(10-18-00)$. 


\section{BACKGROUND}

Since the very first reflection seismic line was made for subsurface exploration, geologists and geophysicists have wanted better quality reflection data, greater resolution of the subsurface, and, of course, lower costs. As technology improved from single-channel analog recorders to large multi-channel digital recording systems, so did the ability of geoscientists to image the earth and find more reserves in shorter periods of time. Today, exploration costs worldwide are in decline, largely credited to 3D seismic surveys. As good as the current technology is, one technical limitation remains - the data must be ultimately acquired at the earth's surface.

Borehole seismic surveys started some two decades ago with vertical seismic profiles (VSPs). Several of the major petroleum companies began significant efforts within their own research laboratories to examine the promise of this new tool. The early systems were much like surface seismic, with a single receiver put into a well and a source on the surface. By recording data at various depths, something like a narrow seismic line could be produced that would allow geoscientists to tie seismic data to known rock units in the proximity of the well. An additional benefit was reducing surface effects. Weathered zones, or other low-velocity zones that absorb significant amounts of energy, were only penetrated once-with the down-going energy - rather than twice as with typical surface-acquired data. Reverse VSP (RVSP) was designed as an attempt to get more energy to the formations of interest by putting a seismic source into the borehole with the receivers on the surface. Results were generally no better than standard VSPs. From an economic point of view, VSPs and RVSPs provided data that enabled explorers to map prospective horizons with greater accuracy and confidence, and provided somewhat better resolution of the events of interest, such as producing zones.

Given the success of VSPs, which are common today, geophysicists demanded even more from borehole seismic surveys. In the mid-1980s, researchers at the laboratories of various major petroleum companies independently designed and tested many kinds of seismic receivers and sources. These systems demonstrated that surveyors could shoot from one well to another. Two different, but similar, types of data were effectively gathered in these early tests. One provided what amounted to a seismic tomogram of the earth between the two wells. While interesting, these tomogram surveys were quickly recognized as being of limited value because the seismic energy could be effectively trapped by highvelocity formations that act as a wave-guide. The second type of data collected, however, was far more interesting. These data were a reflection record, similar to data gathered from the surface but without the high attenuation that typifies surface-acquired data in many areas. Consequently, much higher frequency

data could be recorded, providing finer resolution of the subsurface structure. Collecting this second type of data is now called a cross-well seismic survey.

In these surveys, one or more receivers are placed in a well, and a source is put into a second well (Figure 1). During the survey, both the receiver and source are moved to cover the vertical interval of interest. Although cross-well surveys produced significant quantities of high-quality data, they were expensive. Simply put, two well bores were tied up for too long, to get data that was yet to be proven useful. Henry Tan, then with Amoco, recalled "Our Dutch operations group had us work up a survey estimate; it was $\$ 200,000$. The rig time alone would cost an additional $\$ 800,000$ so the project was scrapped." It seemed the problem was not the science but rather the hardware to enable a very large amount of data to be collected rapidly. 


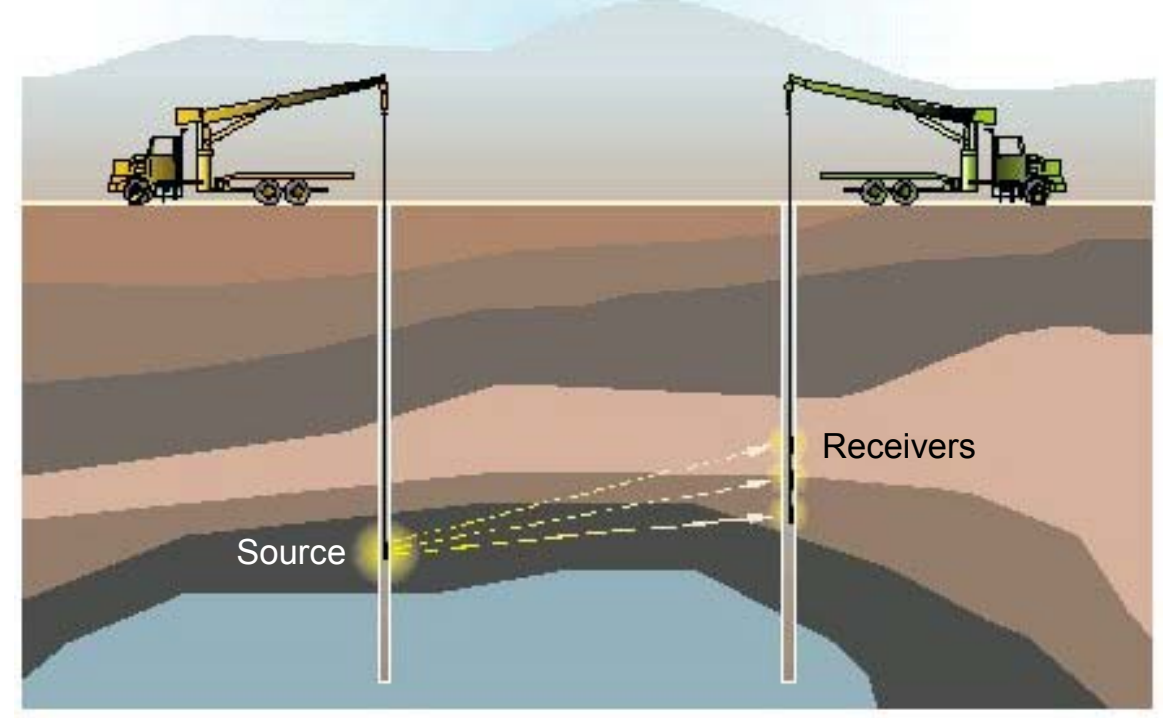

Figure 1. Schematic diagram of a typical cross-well seismic survey.

An additional impediment to realizing the promise of cross-well seismic surveys was that there were no readily available seismic sources for borehole deployment. Seismic sources used for RVSPs were problematic experiments, at best. In simplest terms, the quality of any seismic survey depends on the amount of energy put into the earth. For surface surveys, this is not a problem. In early seismic surveys, workers used dynamite. In areas where dynamite was not allowed, such as in urban areas, other methods, e.g. vibrators or air guns, were used very effectively. Obviously, dynamite is not a viable option for use in a producing well. Texaco experimented extensively with air guns while Conoco developed an orbital borehole vibrator. The minimum distances between wells became the yardstick by which these sources were measured. Cross-well surveying's greatest promise seems to lie in producing fields, so well spacing would determine if a cross-well survey is an option in determining reservoir continuity or the location of a flood front. Unfortunately, internal development of such systems by the major petroleum companies was cancelled as their research labs were shut down. ${ }^{1}$

A major cost of collecting borehole seismic data in producing wells is the cost of lost or delayed production. In typical producing fields, various tubing assemblies and other downhole equipment would also have to be removed. Consequently, it is desirable to minimize the number of wells taken out of operation, while still getting the best possible seismic data. One solution is to put the source and receiver in the same well, hence acquiring the data with only half of the wells involved. While attractive at first glance, one major technical hurdle must be overcome - preventing the energy that propagates directly from the source to the receivers without leaving the borehole, generally referred to as tube waves (TW), from interfering with the desired signals.

That a significant amount of production in the Gulf of Mexico is associated with salt domes is another reason for developing a single-well system. Salt domes are density-driven intrusions of salt that are buoyant relative to the surrounding sediments. Their formation takes place over geologic time frames. Consequently, the generation and migration of oil and gas are often significantly affected by these upwardly moving bodies so that oil and gas deposits are concentrated along the sides or flanks of these salt intrusions. Conventional seismic data taken on the earth's surface are biased towards imaging flat- 
lying geologic structures. Very steeply dipping or vertical structures are nearly impossible to image from the surface. However, if the geometry of a surface survey could be rotated vertically, the steep flanks of salt domes could be imaged (Figure 2). This would allow far better development and extraction of the reserves trapped up against the salt face. These two primary drivers, then, were why industry was so interested in performing seismic imaging from a single wellbore.

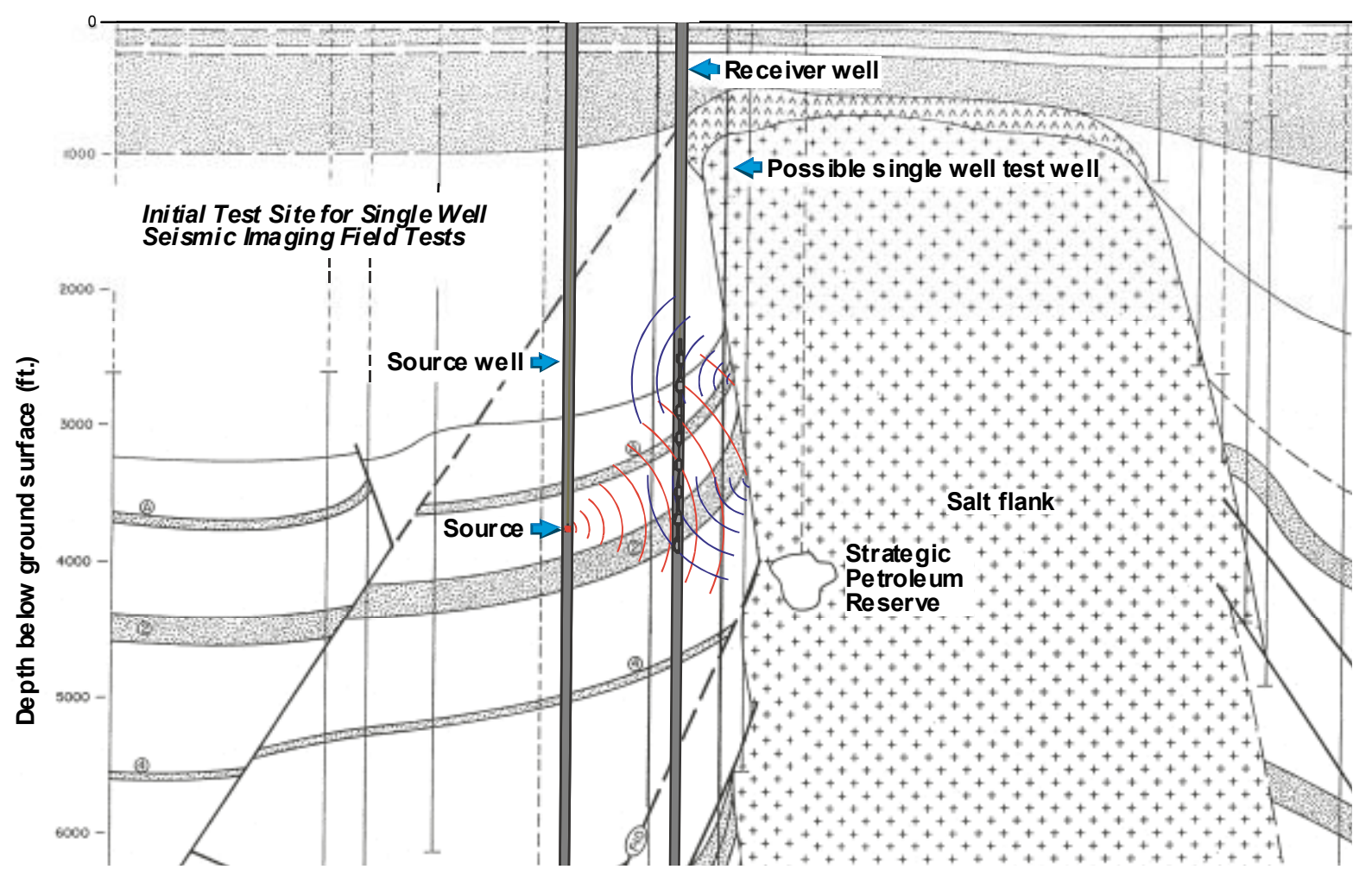

Figure 2. Cross-section of a portion of the Bayou Choctaw oil field in southern Louisiana. This field produces from sand reservoirs that are deformed and truncated by the growth of a salt dome. Accurate location of the termination points is important to maximize recovery of the oil and gas. In this particular diagram, the initial SWSI trials had a source in one well and receivers in a nearby well because the tube wave problem was too severe to have both source and receiver in the same well.

Reducing the cost of lost production and obtaining better data around salt domes are the two primary reasons industry is interested in performing seismic imaging from a single wellbore. But, as Sen Chen of Exxon remarked of earlier attempts to acquire single-well data, TWs would swamp all (any) data that might be coming into the receivers. The amplitude of this source of noise was so great, that it was impossible to determine if any reflections were present. Chen's experience was echoed by all others who had also tried to acquire data in this fashion. 


\section{THE TUBE WAVE PROBLEM}

Simply stated, seismic signals transmitted and reflected at the borehole confound the data being received during single-well seismic imaging. The energy that contains the information of interest is the energy that leaves the borehole, reflects off a surface at some distance from the borehole, and then returns to the borehole. Based on modeling studies, only about $5 \%$ of the energy leaves the borehole. ${ }^{2,3}$ The energy that does radiate away is decreasing in intensity. Some of that energy will encounter different media boundaries and will be reflected. The reflected energy travels back towards the borehole, continuing to decrease in intensity, and encounters the cement and steel casing of the wellbore, where some is reflected and some enters the borehole. The impingement of energy on the borehole creates very small motions of the borehole, which geophones detect as motion and hydrophones detect as pressure. All during the recording (listening) time, about $95 \%$ of the seismic source's energy is bouncing up and down the borehole, which is an excellent waveguide. Consequently, acoustic signals arriving either directly from the source via the borehole fluid or indirectly from the borehole itself interfere with the signals arriving from the reflections of interest outside the well. Surface surveys have been suspended due to high noise created by wind, traffic, or other cultural activity nearby or overhead. Unfortunately, in a singlewell configuration, the source of the energy and noise is right next to the receivers. The problem is not unlike trying to hear the echo of a whisper across a stadium during the game-winning score of the Super Bowl!

The unwanted signals, of which there are several types, are generally referred to as tube waves or TWs. Filtering TWs through data processing has proven to be nearly useless. Consequently, this interference poses significant difficulties to an otherwise cost-effective survey technique.

\subsection{What is a Tube Wave-A Mechanical Perspective}

From a mechanical perspective, a tube wave is a disturbance that propagates along the discontinuity in the earth formed by a well bore; it can be witnessed both from inside and outside the borehole. ${ }^{4}$ TWs appear to travel just slower than the speed of sound in water, and they seem to be made up of P-waves in the borehole fluid and mostly S-waves in the casing, depending on the source type. The media surrounding the borehole also channels the TW energy as S-waves, and potentially P-waves if the source or reflections can generate them. It is usually believed that the bulk of TW energy is transmitted in the borehole fluid (again depending on the type of source), and several INEEL tests demonstrated that a source could impart significant energy exclusively into the fluid. Studies of piping system "water hammer" indicate that similar physics are evident in fluid-borne P-waves. ${ }^{5}$ However, the distribution of energy between the liquid and the solid varies with the configuration of the source and how the source imparts wave energy to the borehole.

If the source creates a change in volume (mono-pole), it will impart a P-wave disturbance to the fluid surrounding it. Regardless of how spherically uniform the pressure disturbance is, it will be efficiently communicated along the axis of the bore. The radial disturbance will impart a signal in the borehole wall, which will create a ring of stress that propagates outward as P-waves and at $45^{\circ}$ as S-waves. The S-waves cannot propagate at interfaces of zero shear stiffness and "reflect", so they are trapped at interface features such as the casing. The S-waves then follow the borehole at a speed similar to that of the P-wave disturbance in the water. A dipolar source, such as an oscillation, creates a directional disturbance with P-waves emanating from a surface of different impedance (than water) and varying momentum. Paulsson ${ }^{6}$ stated that a vertical dipolar source did not create TWs. It is more likely that a clamped vertical dipole source creates reduced TWs in the fluid because shear waves cannot transmit momentum into fluid. A horizontally rotating dipolar source, on the other hand, creates a local Pwave disturbance on the borehole wall (positive and negative) that rotates with the source. So, as the 
shear disturbance propagates away (up and down), a helical disturbance pattern is produced. Some contradiction exists as to this being a torsion stress since it should look more like a helical ring than a torsion wall-stress. ${ }^{7}$

The S- and P-waves in the casing and media surrounding the borehole reflect and refract, as expected. Together with the P-wave in the water, they make up the TW phenomenon. In most boreholes, TWs are not predictable or mathematically filterable without significant compromise. Field experience indicates that, as expected, changes in the impedance of the wave propagating media affect the wave transmission. Also as expected, higher impedance tends to reflect the pressure disturbance (same polarity) and lower impedance tends to absorb and create a rarefied disturbance (reversed polarity). The impedance of a medium is a momentum exchange property (density times speed of sound), and the frequencyamplitude relationships bear the energy function. The appropriate length of a reflector is best considered to be frequency specific for reflective/transmitted re-emissions, as indicated by transmission equation below. ${ }^{8}$

$$
\alpha_{\mathrm{t}}:=\frac{4}{4 \cdot \cos \left(\mathrm{k}_{2} \mathrm{~L}\right)^{2}+\left(\frac{\rho_{2} \cdot \mathrm{c}_{2}}{\rho_{1} \cdot \mathrm{c}_{1}}+\frac{\rho_{1} \cdot \mathrm{c}_{1}}{\rho_{2} \cdot \mathrm{c}_{2}}\right)^{2} \cdot\left(\sin \left(\mathrm{k}_{2} \cdot \mathrm{L}\right)^{2}\right)}
$$

Transmissibility, $\alpha_{t}$, is a function of the transmission ratio to incoming signal, where $\rho$ is density, $L$ is length of impedance mismatch, $k$ is inverse of wavelength, and $c$ is the speed of sound. The transmission of acoustic energy is the transmission of strain energy. The higher the stiffness of a media (bulk modulus for P-waves, rigidity modulus for S-waves) the shorter (both time and distance) the rise time of strain, and as a consequence, the faster the transmission. The ability to absorb energy is the ability to convert the transmitted work (PV) to heat, as opposed to more PV work in the form of reflection or transmission. The PV work can be a modified frequency based on the response frequency of the impedance discontinuity. ${ }^{\mathrm{a}}$ The conversion of energy to heat can be through viscous damping or thermodynamic functions.

\subsection{Theory of Suppression}

The undesired consequence of a TW may be the result of any combination of the primary acoustic signals in the communicating media and all the reflections from within and without the borehole. It may be the result of specific harmonics relative to the source and/or receiver and/or media. So, creating a universal TW suppression system that always effectively mitigates a TW from inside the borehole is probably not possible. Nevertheless, absorption of strain energy in the fluid is possible, and can best be accomplished through accumulation and viscous losses resulting from accumulation. If an accumulator can be configured with matching impedance so that strain energy is converted to heat before it can be reemitted as new strain, it will absorb some of the signal. This is the concept behind controlling water hammer using accumulators. An accumulator with impedance lower than that of the bore fluid may be acceptable because the re-transmission (reflection with reversed polarity) will likely be of low efficiency (inelastic) especially with the added effects of viscous drag. The accumulator concept is feasible for suppressing fluid-borne signals. However, it is unlikely that one can extract the strain energy from the casing (continuous solid, high impedance, system) without (at best) changing harmonics and creating

a. $\mathrm{PV}: \mathrm{P}=$ pressure, $\mathrm{V}=$ Volume. $\mathrm{PV}$ is equal to force times distance if distance is integrated in all directions. 
reflection. Furthermore, a method that uses harmonic changes and reflection in a continuous system (e.g. well casing and cementing) would still not eliminate transmission in the continuous system. Only a break or a step change in impedance (e.g. a diameter transition) will affect the transmission of the solid-borne disturbance.

Complete TW quiescence does not seem possible without discontinuities in both the fluid and solid environment. However, wells without metal casing may offer elasticity that cannot as easily support solid-borne strain energy or fluid-borne pressure transmission.

Viscous damping is not a significant factor in TW suppression without accumulation. The relative displacement distances of matter in incompressible materials are so small that frictional losses are essentially nonexistent, whereas viscous damping is significant when compressibility is such that those displacement distances are large. Because of the long wavelengths in seismology, the relative motion between two neighboring components of wave-transmitting material is effectively zero. In the much shorter wavelengths of ultrasonics, this is not true. Suspensions can even create polishing action with the passing of ultrasonic energy, and accordingly ultrasonic disturbances deposit heat and damp out quickly. Internal damping is simply not a factor for long wavelengths in incompressible materials.

Solids and liquids absorb and re-emit strain energy through stress-strain relationships. This is a function of their modulus (bulk for liquids and all types for solids). Seismic surveys demonstrate these principles in a macroscopic way. Solid objects that are capable of any significant suppression or reflection in seismology are large, and not easily deployed in a borehole. Media of differing speeds of sound, for example, can create destructive interference, regardless of damping capability. This occurs in nature. Destructive interference can dissipate some seismic energy, but its effectiveness is a function of frequency, length, and position relative to the source and receivers. The long wavelengths of seismology and the relatively small differences in acoustic impedance require large distances for the destructive interference patterns to occur. Compressible matter, however, will behave differently.

Gases change volume more easily than solids and liquids. When a pressure disturbance in a liquid encounters a gas volume, it can displace atoms of the gas with little or no effect on the rest of the gas volume. This effect is a function of the pressure and the volume of the gas. However, placing the gas volume inside an enclosure may affect the overall compressibility of the gas. If the enclosure is rigid, the gas volume cannot compress and the strain energy carried in the fluid will simply be transmitted through the rigid enclosure back into the fluid. The strain energy may reflect if the enclosure is sufficiently long relative to the wavelength, but the presence of a gas volume will have little effect because the effective "bulk" modulus of the whole volume is largely the chamber. If a flexible medium is used to contain the gas volume, it should be configured to allow compression even with small pressure changes. This, however, is only possible if the enclosure material is not strained. If the material is strained, such as with a stretched elastomer, the gas volume cannot be effectively compressed until the strain of the material is overcome. Small pressure disturbances of acoustic energy do not have sufficient differential pressure to un-stretch the elastomer and compress the gas. Consequently, the energy is working against the flexure and tension modulus of the elastomer, not the gas. A relaxed (no tension), low-flexure modulus (nonrigid) enclosure can effectively change volume with little strain energy being absorbed by enclosure, and the bulk of the energy will be, at least for a time, absorbed in the gas volume. Experiments performed using high-speed photography demonstrated the well-known phenomenon that gas bubbles (such as those resulting from air-gun operation) suppress pressure waves. The gas bubbles visibly deform as waves pass. $^{9}$

The ability of a gas to "absorb" the energy of an acoustic signal is a function of pressure and volume. If a gas-filled (but not stretched) flexible enclosure is placed at great depth, it can still compress, but it cannot compress as much for the same pressure disturbance and volume. Nevertheless, even a 
highly compressed volume will be more compressible than liquids and solids. As long as the gas employed follows the Ideal Gas Laws, the relationship between pressure absorbed and volume will be linear and pressure will be the inverse of volume. From a design point of view, double the depth, double the volume of gas. Consequently, the mass of gas required will increase with the square of depth. If the diameter is limited, increasing the length will be effective. However, excessively large volumes may perform like an open-ended pipe, causing a reversed sign (180 degree phase) wave reflection. The length of a gas volume will affect the reflection response as a function of the frequency, but we anticipate inelastic strain transmission. Therefore, reflection/transmission should be inhibited either way, but it does argue for a limit on length. The more desirable configuration is one that does not completely (i.e. efficiently) impose either negative or positive reflection. Consequently, $1 / 4$ to $1 / 2$ wavelength would be ideal, but with the range of frequencies required in seismology, length optimizing is difficult.

Furthermore, considering the difficulty of getting a gas volume deep under the surface, and the low frequencies (long wavelengths) of seismology, the design length will likely be significantly less than $1 / 4$ wavelength. These considerations formed the hypothetical basis for the INEEL task. 


\section{INEEL TASK}

The mission of INEEL researchers was to evaluate TW control, and to design, build, and test passive tools that could mitigate, attenuate, or otherwise preclude unwanted TW energy from masking the signals of interest during single well seismic imaging. The INEEL efforts were not the first attempt to solve this problem. A number of U.S. patents have been issued on various devices attempting to mitigate tube waves. ${ }^{10,11,12,13,14}$ However, none of these methods proved sufficiently successful for broad-based use by the industry. The ultimate INEEL goal was to develop a system that could be deployed to operational depths on a conventional wireline, and that could attenuate/mitigate the undesirable effects of a TW during seismic surveys with minimal interfacing with the surface. Other operational considerations, based on industry specifications, included:

- Maximum diametral envelope of 4.4 inches

- $\quad$ Operate up to $125^{\circ} \mathrm{C}$

- $\quad 10,000$ psi

- $\quad$ Corrosion-resistant materials compatible with environment

- Compatible with all seismic sources currently in use

- $\quad$ Highly reliable (in measurable units, if possible)

- 100 (or more) uses before failure desirable

- Fail safe and recoverable without destroying system

- If at all possible, the system would be passive, requiring no electrical or mechanical power from the surface.

A variety of devices and materials in a variety of configurations were tested. Some configurations attempted to fill the borehole while others simply attempted to inhibit acoustic energy transmission by being in the transmission path. In the shallow INEEL test wells, a simple, inflatable bladder or a trapped gas volume provided significant suppression $(20$ or more $\mathrm{dB}$ ), especially of higher frequencies $(>50 \mathrm{~Hz})$ (Figure 3). These devices may attenuate wellbore signals by reflection, destructive interference, and/or accumulation/damping of some of the energy. Other devices tested at the INEEL appear to provide no suppression.

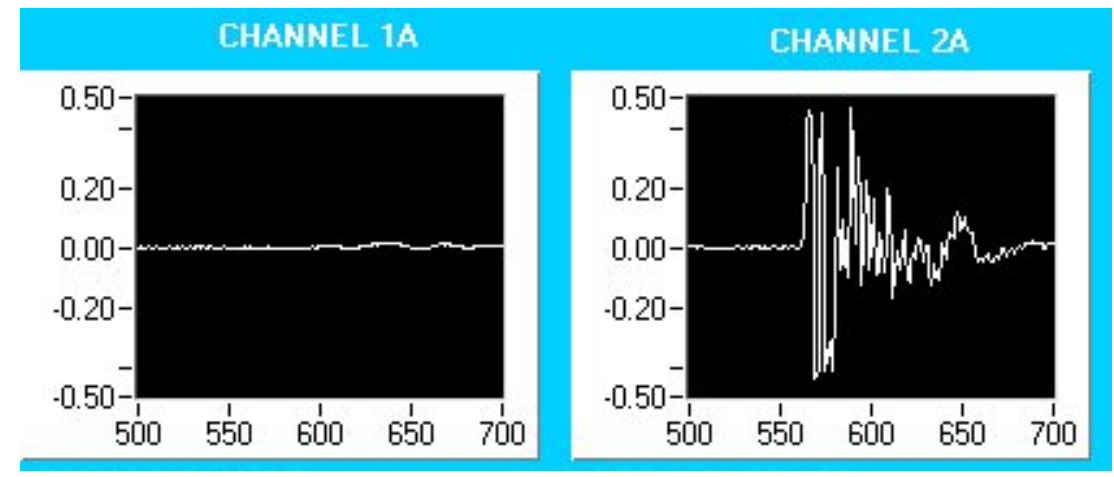

Figure 3. Hydrophone traces. Channel 1 is the lower of two hydrophones separated by a 15 -foot jumper cable carrying a diaphragm suppressor. A piezoelectric source is used above the channel 2 hydrophone. 


\subsection{Laboratory Tests}

To better identify the components of the TW problem, we performed several simple laboratory experiments. We connected two pieces of pipe, filled them with water, affixed hydrophones at four locations along the pipes, and introduced a pressure pulse through a diaphragm at one end (Figure 4). Tests were next performed with an inflated bladder in the pipes. In both cases, pressure pulses were equally detected by all hydrophones. In the third set of experiments, the pipes were separated at the flanged joint so that the only contact between the pipes was through the inflated bladder. In these experiments, essentially no pressure pulse was recorded by the hydrophones downstream of the pipe break.
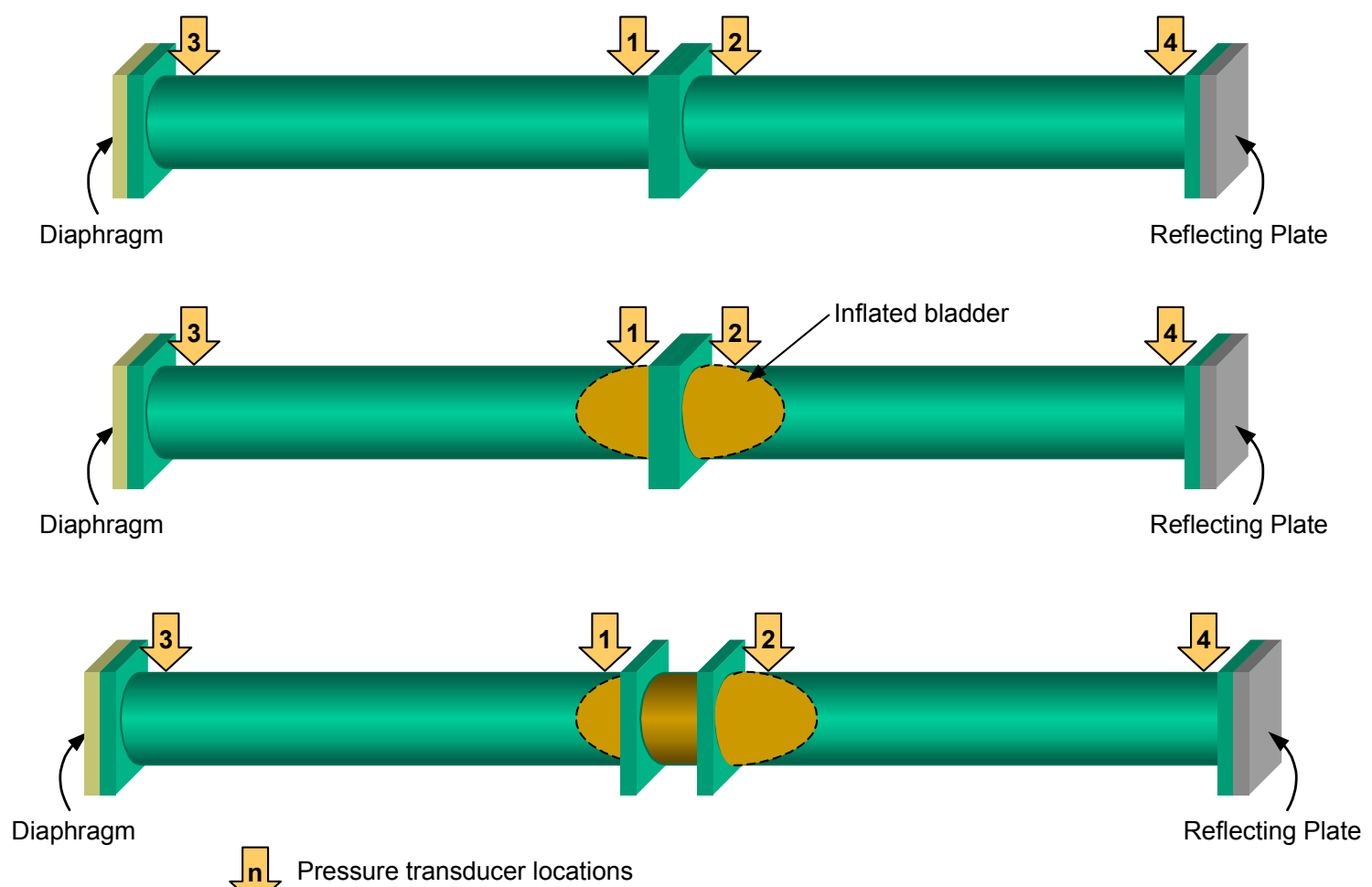

Figure 4. Laboratory apparatus for quick screening of tube-wave suppression. Each PVC pipe is 6-in. in diameter and 10-foot long with flanges on both ends. Pressure transducers were located near the diaphragm (No. 3), on either side of the connecting flanges (Nos. 1 and 2), and near the end capped by a reflecting plate (No. 4). Pressure pulses were introduced at the diaphragm on the left and propagated to the right.

These simple experiments demonstrated that although a significant component of TW energy can travel in the water column, energy also travels through the pipe itself. Initially, both types of energy would have to be addressed until a device could be field tested to determine which of the two interfering energy types (fluid-borne or pipe-borne) could be effectively eliminated (Figure 5). 

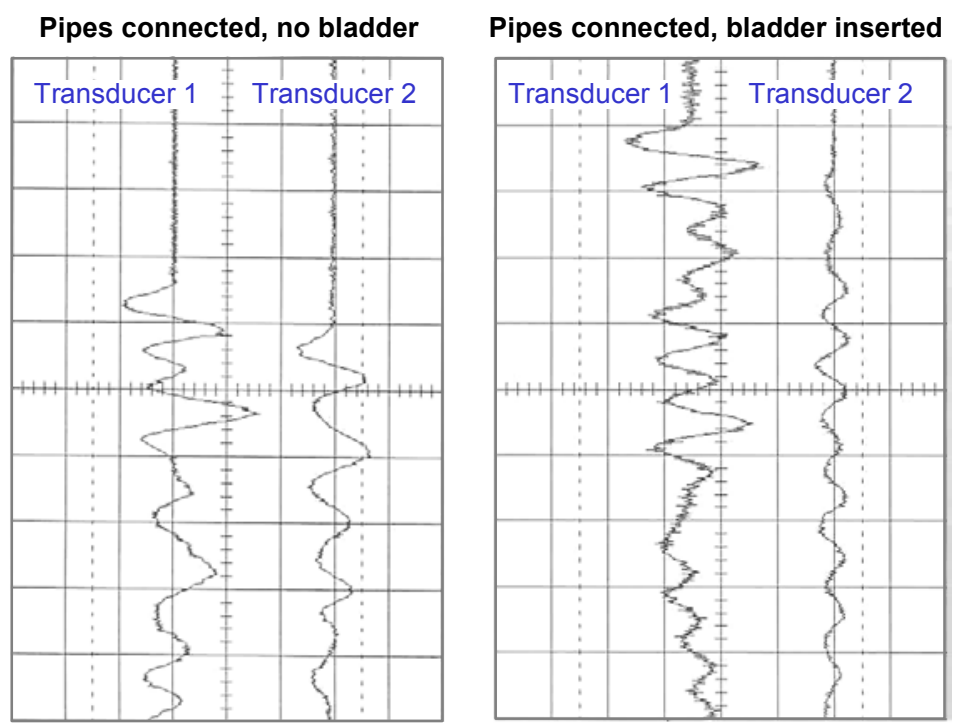

Pipes separated, bladder inserted

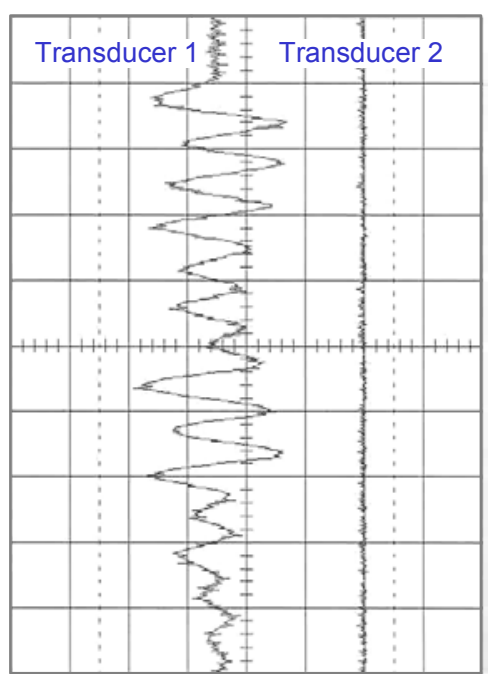

Figure 5. Output traces of pressure transducers on either side of central flange. Transducer 1 is on the "upstream" side from which energy is propagating; Transducer 2 is on the "downstream" side. Each horizontal division is one microsecond, each vertical division is $20 \mathrm{mV}$.

\subsection{Tests in INEEL Wells}

\subsubsection{Test Wells and Equipment}

Two instrumented wells were constructed to provide both cross-well opportunities and redundancy. Both wells were equipped with redundant three-component geophone sets welded to the casing and subsequently cemented into the annular space between the steel case and the earth. These "reference" sondes were connected to amplifiers located at the ground level. A pair of INEEL-designed and constructed, wireline deployed, hydrophones were also used. A PC-based data acquisition system (DAS) with six-channel capability for simultaneous acquisition of two, three-component modules was procured. Most tests, however, were performed using the two hydrophones and only two of the six channels on the DAS. One channel recorded the unfiltered signal and the other recorded the signal that passed the test article. The implanted geophones were used to examine the casing/grouting response to tube wave phenomena. A pumping system to transfer water in and out of the wells allowed wet- and dry-well tests to be performed.

Initially only two source types were used to initiate a TW, later other source types, weight drop and subsurface impulse, were used to examine the efficiency of the test device on other frequency spectra, geophones, and casing-borne waves. The initial two sources were an explosive source (a .22 caliber blank) and a piezoelectric source. Because hydrophones are pressure sensitive rather than motion sensitive, and because they are omni-directional, we thought these would provide sufficient data for the initial tests. Later, however, the fixed geophone modules and INEEL-developed clamped geophone modules were used to examine the effect of the TW on the well casing and on clamped geophones.

\subsubsection{Field Tests in INEEL Wells}

The initial field tests were designed to examine the bore fluid portion of the TW phenomenon. The explosive source was configured to produce a strong fluid-borne signal with little consideration of 
wave transmission in solid media. Hydrophones were chosen to sense the fluid-borne acoustic signal. Some early tests employed a small piezoelectric source; its acoustic signature included higher frequencies that were more easily attenuated as illustrated in Figure 3. We attempted to reflect/suppress the downgoing signal by blocking the path, silencing with "mufflers", creating destructive interference, inducing impedance change reflection, and providing a gas to undergo energy-adsorbing volume change.

Late in the program, industrial associates questioned what effects, if any, the INEEL-developed tools may have on the solid-borne portion of the TW. Geophones were then used to examine the solidborne disturbance, and none was found. Even a strong signal, as registered by the hydrophone, could not be detected by geophones located just outside the casing. Weight drop tests were performed to examine the sensitivity of the receivers and it was noted that the sensitivities of hydrophones and geophones were similar.

\subsubsection{Test Results}

Early INEEL design efforts were directed towards controlling the tube-wave disturbance by reflecting it away from the receivers. This approach raised a number of questions. If a reflective discontinuity in one well creates a localized quiescence suitable for seismic imaging, will it do so for all locations, all frequencies, and all wells? In the process of reflecting a pressure disturbance do we inadvertently create a P-wave coupling to the casing? If so, this argues for not fully blocking the area of the bore. ${ }^{\mathrm{b}}$ Furthermore, can a reflective discontinuity be replicated with deployable devices? In addition, one can ask, and it is not answered here, does the reflection from a borehole "reflector" tool include all components of the TW? If the seismic imaging equipment includes tightly clamped geophones, casing disturbances will be a problem even without a dominant water-borne wave. In general terms, reflection will not necessarily remove wave energy, and quiescent zones will be accompanied by zones of increased amplitude caused by interference patterns of resonating waves and possibly even modified frequencies due to re-emissions. This is the case when the reflection is efficient (i.e., PV work is not converted to heat).

Interference may be used to suppress the wave energy reaching a receiver. Although interference and attenuation are not equal, that reduction could be measured as attenuation. However, interference attenuation that results from reflection does not reduce the overall energy and trades quiet zones for zones of increased amplitude. Attempts to use the quiescent zone may frustrate the imaging process by subjecting the data to a myriad of undamped, inconsistent, unpredictable, and likely casing-coupled signals. Even in the shallow INEEL test wells, interference patterns are evident (Figure 6). Suppression of the fluid-borne disturbance by reflection is a function of the positions of the reflector and receiver (test string) in the well (Figure 7). Furthermore, the attenuating device contributes to the overall signature of the well as a function of its position, which, in turn also changes the dominant frequencies as received by the hydrophones. The dominant frequencies appear as a family of curves of increasing frequency as the closest reflection becomes nearer (Figure 8). It appears reasonable that different wells should have similar behaviors but different response frequencies. However, another INEEL test demonstrated inconsistencies that negate this assumption--air accumulation at the bottom of the well created new patterns of suppression and frequency (Figure 9).

b. Casing disturbance control is addressed in "Packing" section, page 18 . 




Figure 6. Attenuation at several depths. Each data point resulted from a test like that illustrated in Figure 3 except that an explosive source (.22 blank) was used. The cyclic behavior of attenuation vs. depth and the amplitude increase (-dB) are indicative of interference patterns. "Nominal depth" is from surface to top of upper hydrophone.

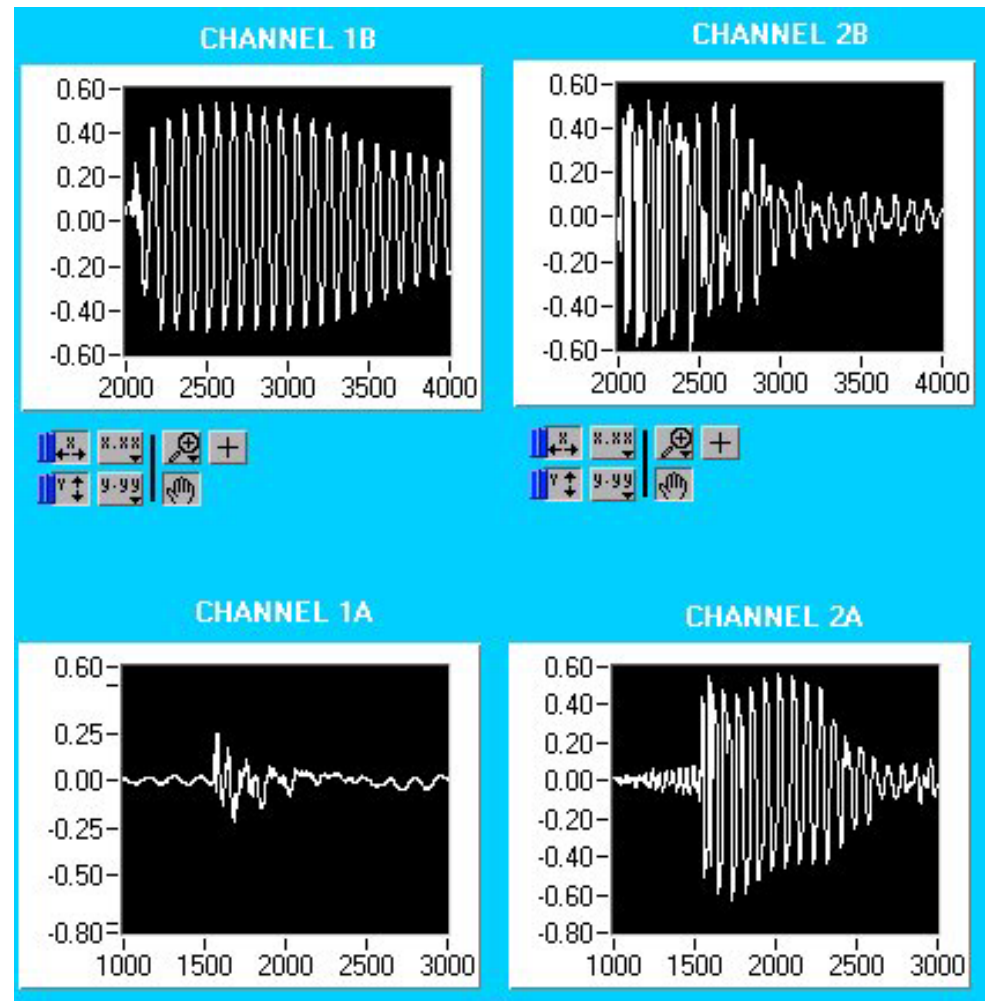

Figure 7. Changing the position of the test string from nominally $37.5 \mathrm{ft}$. for A to $20 \mathrm{ft}$ for B and caused the constructive and destructive interference evident in the differences between the hydrophone signals of Channels 1 and 2. Channel 2 is a $15 \mathrm{ft}$. above Channel 1, and a purged diaphragm suppressor is between them. Explosive source is used. 


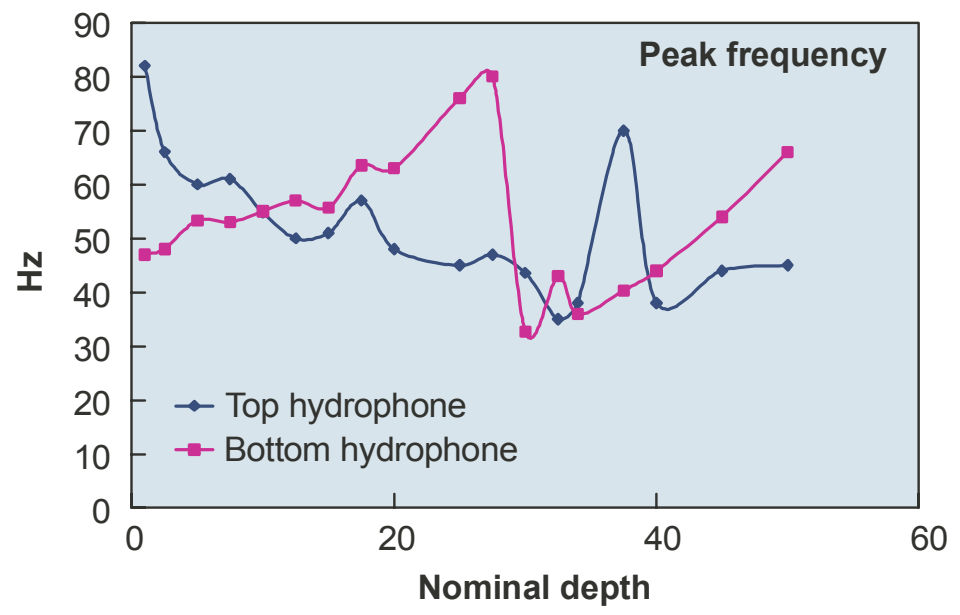

Figure 8. Dominant frequencies recorded by hydrophones with a purged suppressor illustrating the effect of position on frequency. It is speculated that the suppressor changes the resonance characteristics of the well. Explosive source. Secondary frequencies that tend to extrapolate the bottom hydrophone curve to and from discontinuity at $30 \mathrm{ft}$ are not shown.
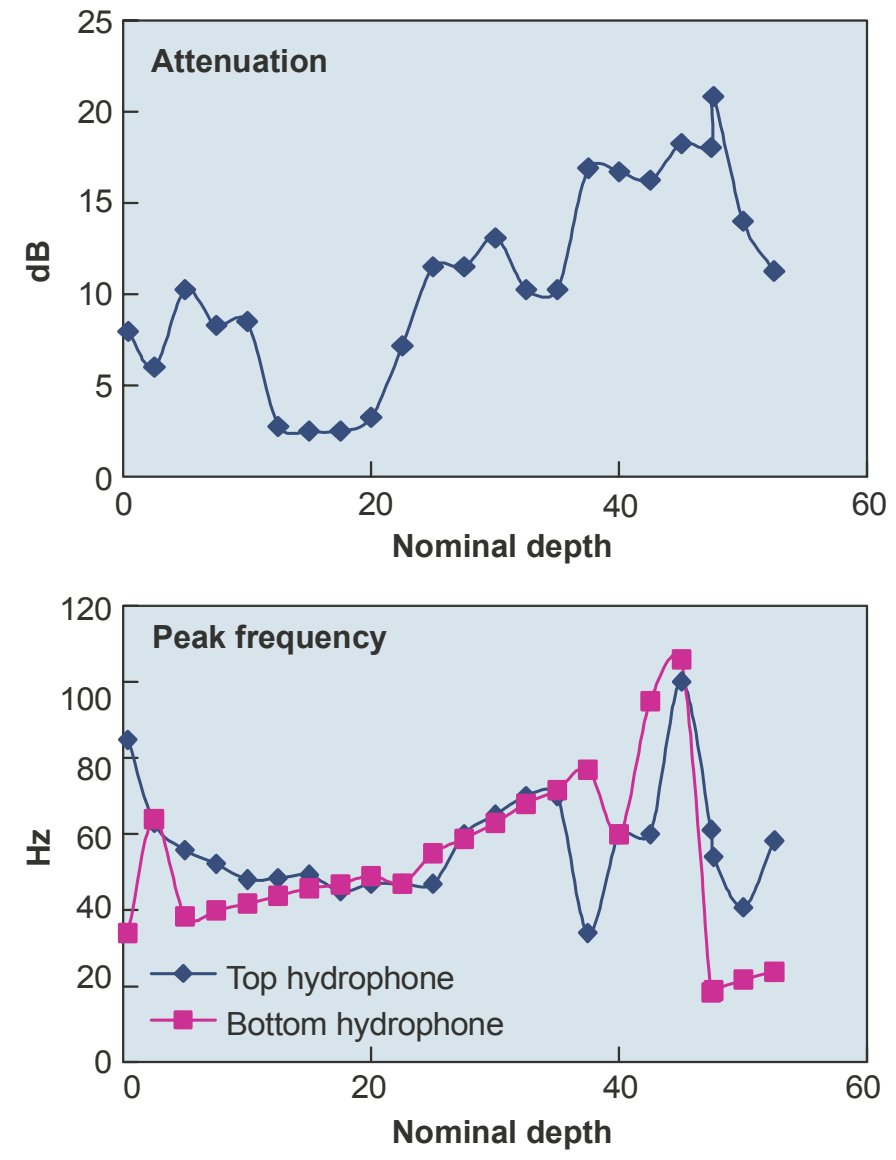

Figure 9. Effect of air accumulation at the bottom of the well. The difference between these graphs and Figures 6 and 8 is due to the change in well character resulting from a compressible volume located at the bottom of the well. The effect should be analogous to a open vs. closed pipe, but more complex; it is not amenable to quantification. 
After evaluating these results, a device that absorbs the acoustic energy seems the better concept. Even when substantial resonating waves occur, a "damping" device quickly removes the disturbance. However, this may not be sufficient. An otherwise effective attenuating device may not decrease the amplitude of the first pressure disturbance, especially if it is of low frequency $(<50 \mathrm{~Hz})$ (Figure 10). On the positive side, however, tightly clamped geophones seem to be effectively isolated by acoustic damping devices even from the first signal (Figure 11). This may be because higher frequencies are easily suppressed and a tightly clamped geophone is more tolerant of low frequencies.

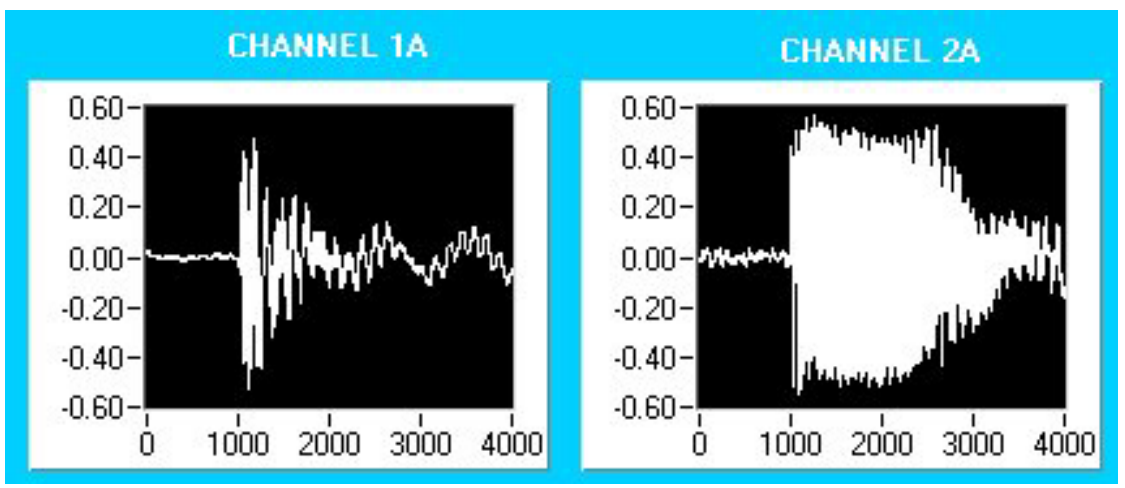

Figure 10. Large magnitudes of energy can be dispositioned without actually reducing amplitude of the initial part of a signal. Explosive source at $25 \mathrm{ft}$.
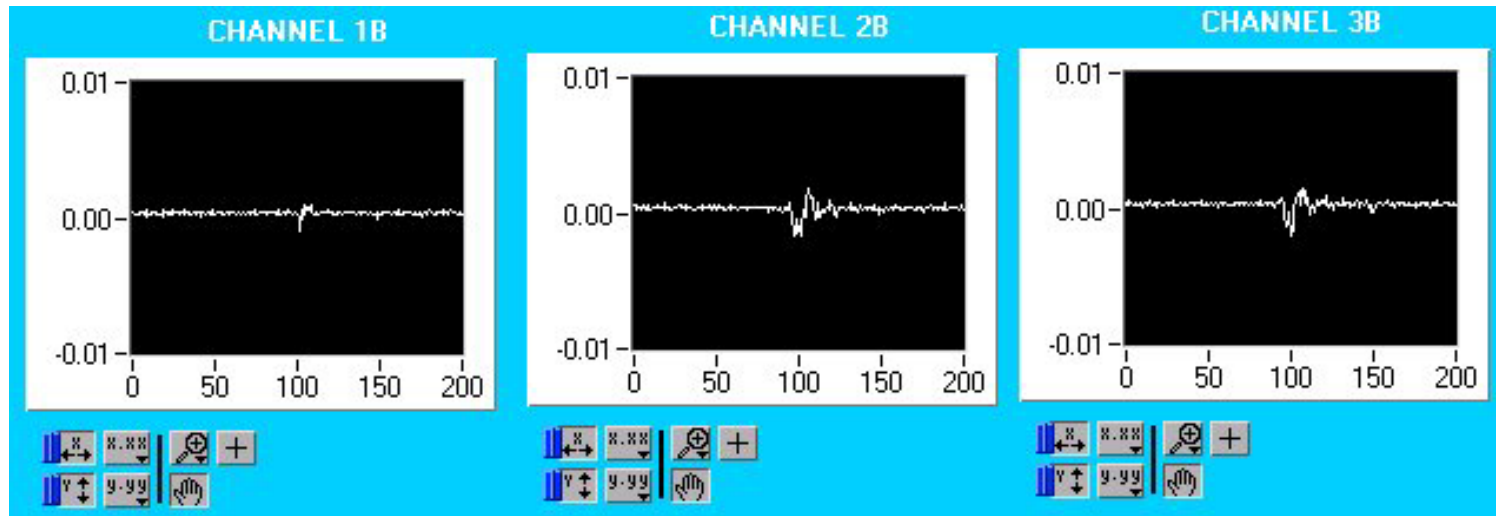

CHANNEL 1A

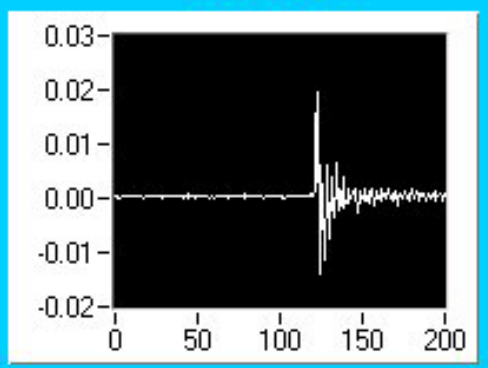

CHANNEL $2 A$

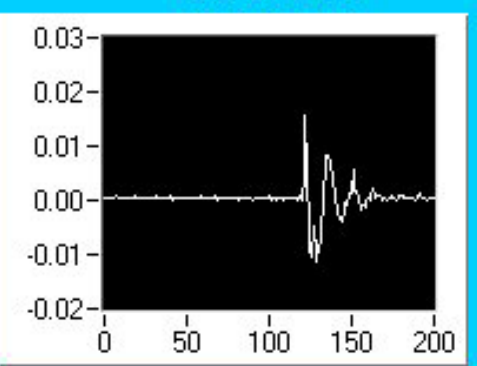

CHANNEL 3 A

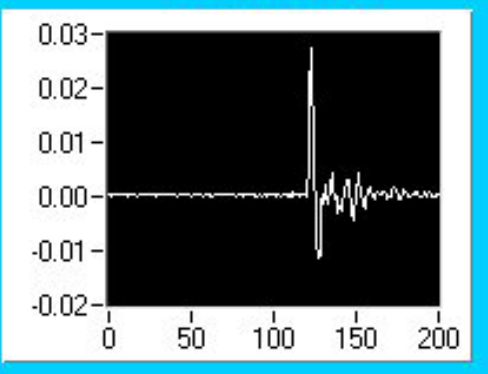

Figure 11. The effect of TWs (suppressed and unsuppressed) on a clamped geophone is shown by these three-axis geophone receiver $(\mathrm{x}, \mathrm{y}, \mathrm{z})$ signals. The "B" signals are suppressed and the "A" signals are not. Explosive source. 


\subsection{Tests at Other Sites}

One suggested approach to controlling TWs is to "pack off" the borehole. Devices called "packers" are used in wells for a variety of reasons. Typically, they possess an inflatable membrane that can, at some differential pressure, expand to fill and even seal a borehole. Most packers are capable of significant pressure differentials to assure sealing/plugging. They are often able to block, reflect, or damp acoustic and vibration disturbances. INEEL constructed a field-test unit to test a TW suppressor of this type at Bayou Choctaw (BC), Louisiana, and Richmond and Bakersfield, California.

\subsubsection{Bayou Choctaw}

INEEL constructed a TW suppressor with a bladder that could be inflated at depths up to $4000 \mathrm{ft}$. Due to various circumstances discussed below, the tests at Bayou Choctaw were inconclusive.

The first suppressor used a solenoid valve to inflate the bladder with a gas from a self-contained pressure chamber. The solenoid valve was powered from the wireline. The suppressor was shipped to Bayou Choctaw to be tested during a limited time window in an LBNL test program. Unfortunately, it was damaged in shipping and field repair was difficult. After repair water leaked into an affected wire junction cavity and compromised the electrical insulation. Further repairs consumed the test window.

Another test window became available, and a second suppressor was assembled with a fundamental design change. INEEL testing had indicated that "soft" gas-filled bladders worked better than tightly stretched ones, and that partial blockage of the bore was as effective as full blockage. The design of the second suppressor used a self-contained gas chamber with a two-stage regulator to fill the gas bladder without stretching it. The design retained the solenoid in the event that downhole activation/deactivation was desired. This feature gave the design versatility at the cost of reliability - the solenoid valve was dropped in subsequent designs. However, the second field test did not occur due to acquisition equipment malfunctions.

Prior to the third attempt to perform a field test, a system checkout test was performed at the Baker Atlas facility in Houston. The INEEL suppressor appeared to operate as intended, but the evidence of a TW and, therefore of TW suppression, was inconclusive. While at the test area, the bladder received apparent sun damage but the blemish did not appear to threaten performance.

The equipment was transported to Bayou Choctaw where the INEEL suppressor was placed in a locking-arm geophone string between the orbital vibrator source and the receiver string. Rather than the usual instrument deployment sequence of a rapid descent to the lowest point of the survey with slow ascent between survey positions, this deployment involved a quick reversal ascent followed by further descent. The suppressor had not been charged sufficiently to account for a reversal. Nevertheless, no significant malfunctions were expected. The surveys began. Because the suppressor was between the source and the receiver, "control" data and "test" data had to be collected on separate test runs. (The INEEL test string, being configured to examine only TWs, places the suppressor between two hydrophones so that real-time comparison is possible.)

As the instrument string was being removed from the well after testing, it was noted that the bladder or its inflation system was leaking. Visual inspection found that the bladder had torn at the sundamaged location. Also, the pressure chamber leaked gas pressure into the electrical cavity, which posed a reliability issue but did not affect the test. Subsequent inspections revealed pressure damage to one of the regulators, and stuck/sticking pressure control valves. These components may have functioned correctly for some portion of the survey. 
The survey data indicated TW presence with and without the INEEL suppressor. ${ }^{15}$ However, the Bayou Choctaw tests results were, arguably, inconclusive because: 1) the failure location and condition (e.g. half filled bladder?) are unknown; 2) there are no real-time comparisons; 3) a bladder is most effective on signals received by hydrophones, but geophones were used; and 4) the orbital vibrator source used produces less problematic fluid-borne signals.

\subsubsection{Richmond and Bakersfield, California}

Another self-contained TW suppressor was created exclusively for field tests in deeper wells. The design retained the soft bladder; added physical protection for the bladder and valving; eliminated the gas leakage pathway to electrical enclosures; changed the first stage regulator to balance pressure; added a new, very sensitive, second stage regulator; added a valve to dump pressure during ascents: and added special valving to allow the bore fluid to transfer the pressurized gas to the bladder. This last feature, planned for deep well use, allows deeper operation than does the pre-charge alone. This feature becomes active when the pre-charge is no longer sufficient.

This suppressor's first deployment was at the LBNL facility at Richmond, California. In the first SWSI test sequence, hydrophone receivers and a piezo orbital vibrator, operated as a single pulse source, were used. Real-time tests could not be performed because the hydrophone string was a single molded assembly and the suppressor could not be placed between hydrophones. Consequently, tests were performed with and without the suppressor. Cross-well tests using another piezo source were also performed. In the second SWSI test sequence, locking arm geophones and the piezo orbital vibrator were used. Cross-well tests were also performed. These tests at Richmond demonstrated TW suppressions of up to $11 \mathrm{~dB}$. Test results are summarized in LBNL's report. ${ }^{16}$

An LBNL survey provided an opportunity for SWSI tests of the TW suppressor at Bakersfield, California. The first tests employed the piezo orbital vibrator, the INEEL suppressor, and Oyo hydrophones. The suppressor was charged to approximately $900 \mathrm{psi}$, and the instrument string was deployed to 2000 feet deep (Figure 12). The survey was performed. Preliminary data indicated that the suppressor reduced the amplitude of the TW compared with previous experience in the same well. When the string was removed, it was noted that the deep-well function had been active.

The suppressor was then removed from the string, and the piezo source and hydrophones were redeployed to measure the TW amplitude without the suppressor. Unfortunately, the hydrophone string leaked, making it inoperable. A "with and without TWS" test was still desirable. Without the hydrophones, the best alternative was the mechanical orbital vibrator (AC-OV) and locking arm geophones. Consequently, the wireline was re-configured for this arrangement plus the TWS. The test was performed without incident. The test was repeated without suppressor. TW suppression of up to $15 \mathrm{~dB}$ was recorded in this test sequence.

Comparisons of the hydrophone data with results from earlier tests without TW suppression indicated a $33 \mathrm{~dB}$ reduction in TW. However, other variables may have affected these results. Nonetheless, it is expected that the TW generated by the piezo orbital vibrator, as recorded by the hydrophones, would be much easier to suppress than that of the mechanical orbital vibrator recorded by geophones. The detailed results of this test can be found in the LBNL report. ${ }^{15}$ 


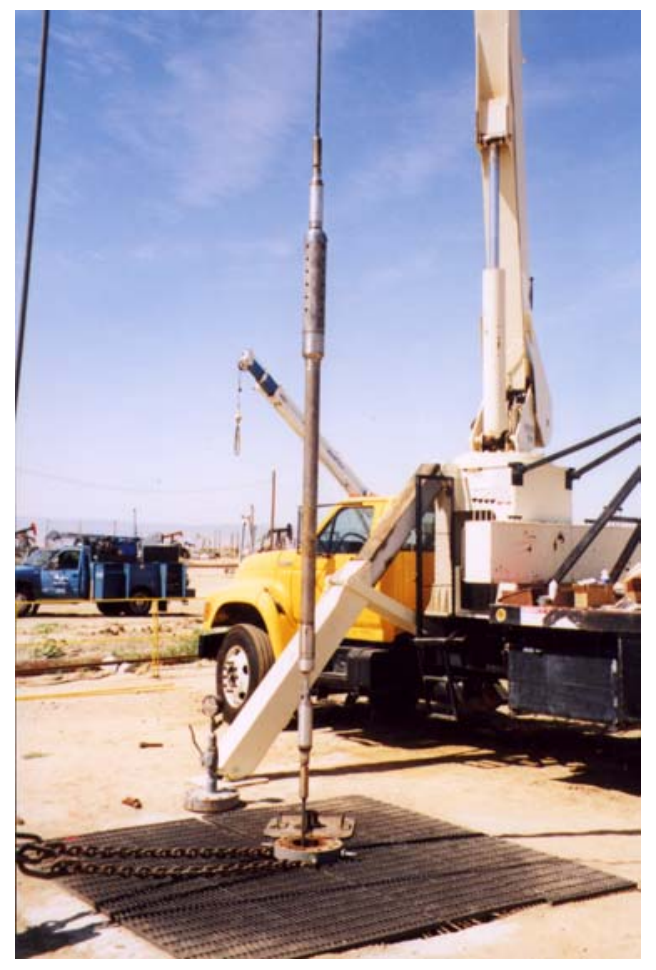

Figure 12. Tube-wave suppressor being deployed at Lost Hills oil field near Bakersfield, CA.

\subsection{Results and Discussion}

\subsubsection{TW Suppression}

The TW problem is complex. Even the most easily analyzed portions of the TW phenomenon can have nebulous real-life components, such as impedance discontinuities in the well and cementing. Nonetheless, manipulation of the TW signal can be demonstrated on a case-by-case basis. In general, methods for controlling TWs may include accumulation (compressible volume), damping, and interference patterns. For any method to work, the strain energy must be absorbed (at least temporarily). Temporary absorption implies re-emission or reflection, and that implies potential changes in the harmonics and not necessarily energy. If the wave energy can be absorbed and converted to heat directly, the TW can be suppressed. Tests of suppression techniques demonstrate this generalization, but how to actually accomplish it in a real world operation with real equipment has not yet been addressed.

4.4.1.1 Packing. Because stretching a flexible volume is not effective, packing is not a way to suppress the fluid-borne portion of the TW. Tests at the INEEL demonstrated this. Effective suppressors performed better when they were not engaged with the casing (Figure 13). In fact, the tighter a bladder is packed, the higher the strain energy in its exposed elastic surfaces. Furthermore, it stands to reason that if one wanted to transmit a pressure disturbance from the bore fluid to the casing one would block the fluid $\mathrm{P}$-wave path. Just as water hammer strains the pipe beginning at the closure, the P-wave will strain the casing at the impedance mismatch - the energy has to go somewhere. In addition, if one wanted to transmit a fluid-borne signal to the casing, would it not be best to connect or couple the impedance mismatch to the casing? 


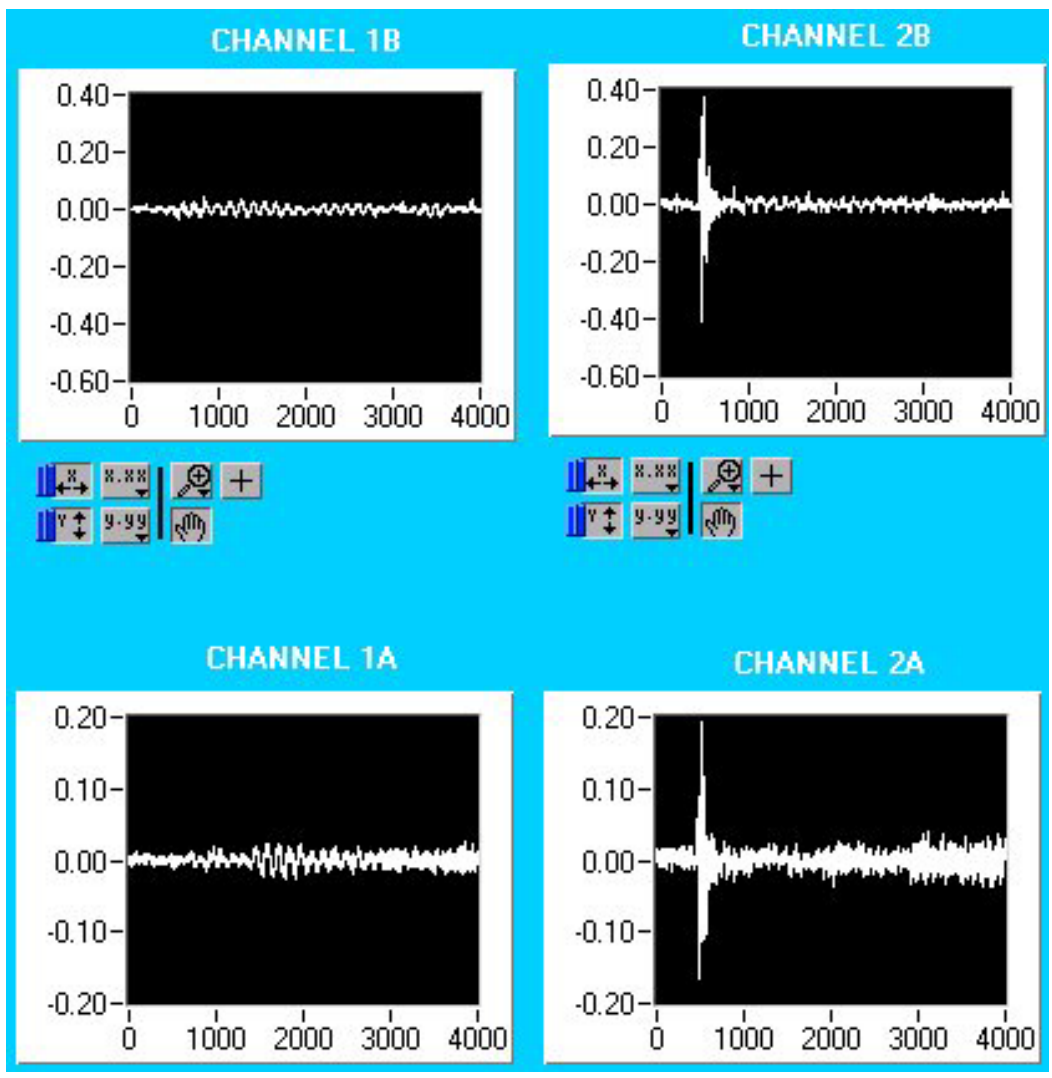

Figure 13. Inflated, but not tight, bladder suppresses hydrophone signal from piezoelectric source. The bladder accumulator was positioned between the two hydrophones. The upper set was recorded with the bladder inflated, but not tight. The lower set was recorded with the bladder "packed" tight in the bore.

Using packers to suppress casing transmissions is not likely to be effectual either. The strain energy transmitted by the casing is of very low displacement and, therefore, communication of significant energy to other components/materials is not likely. INEEL tests using a tightly-packed bladder vs. an inflated but loose bladder demonstrated no real difference in geophone signals (Figure 14). It should be noted again that solid-borne signals are not significant. However, if we address the casing-borne TW, it is every bit as likely that the soft compressible bladder may damp some transverse displacements. This would be because water does not sustain compressive stress in the presence of the compressible volume and becomes a damping medium because it accepts momentum from the casing and transmits it to the gas volume.

One further observation about packers - most are structurally quite strong and non-resilient. Considering the long wavelength signals used in seismology, the impedance mismatch is inadequate to impose much of a discontinuity in the waveguide (fluid and solid) of a well. 


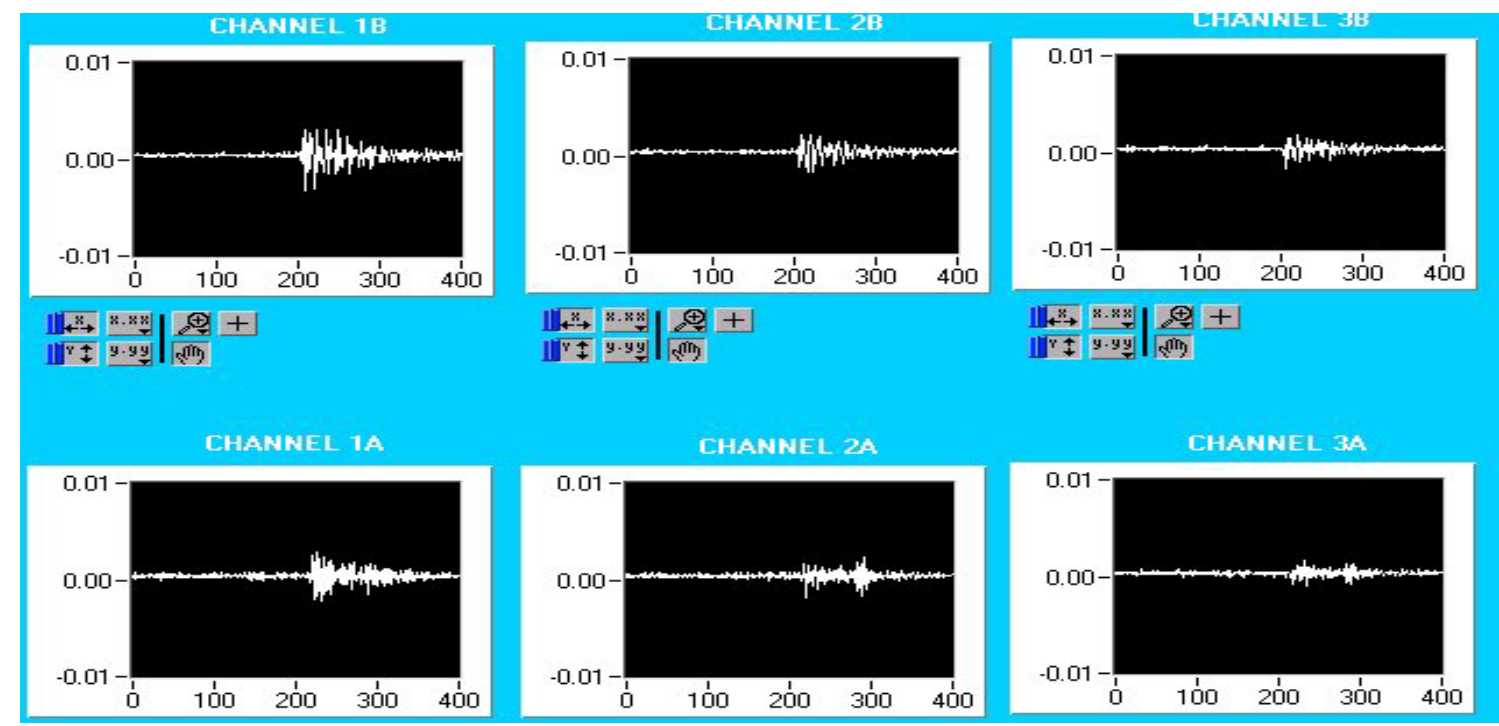

Figure 14. Both sets of $x, y, z$ geophone signals are suppressed by a bladder. The top set is isolated by an inflated, but not packed, bladder and the bottom is isolated by packed bladder. While the signal strength appears lower in the packed case, the difference is small compared to suppressed vs. unsuppressed hydrophones in Figure 13. Explosive source.

4.4.1.2 Inertia and Impedance. Another factor to be considered in designing the geometry of a gas-filled suppressor is apparent inertia. Inertia manifests itself in "impedance". If excessive impedance is encountered there will be little in the way of admittance and absorption. A dense membrane, even if very flexible, is more reflective than a membrane whose impedance matches that of the borehole fluid. Accordingly, a compressible volume with increased impedance will not be as effective as one with reduced or minimal impedance. An example of this is a compressible volume communicating with the borehole fluid via a fluid-filled line. An INEEL test demonstrated that a gas volume collected at the top of a closed pipe provides no suppression, whereas the same gas volume and enclosure, communicating with the borehole fluid via a diaphragm, provides suppression (Figure 15). The difference is that the accumulation of a pressure disturbance cannot occur until some mass of liquid moves along the pipe to compress the gas volume, whereas the diaphragm only has to move to compress the volume. Furthermore, the same closed pipe completely filled with air also provides suppression (Figure 16) because there is minimal inertial mass to move to again compress the gas. It is expected that an air-filled line of small diameter/long length would behave similarly to a larger water-filled line. While this follows the parameters of a Helmholtz resonator, it must first be recognized that the impedance at the interface must be low for the resonator to work at all. Because the fluid filling the line/port is same as that in the borehole, it is likely that impedance match would be approximated by having a port area at least as large as the well bore. This speculation is based on the observation that impedance is a momentum exchange property. For a smaller cross section of water to transmit the signal of a larger cross section, it would have to move faster, which violates the laws of energy conservation. It may also be speculated that reflection (opposite polarity) might be mitigated by spacing ports or using multiple devices. 


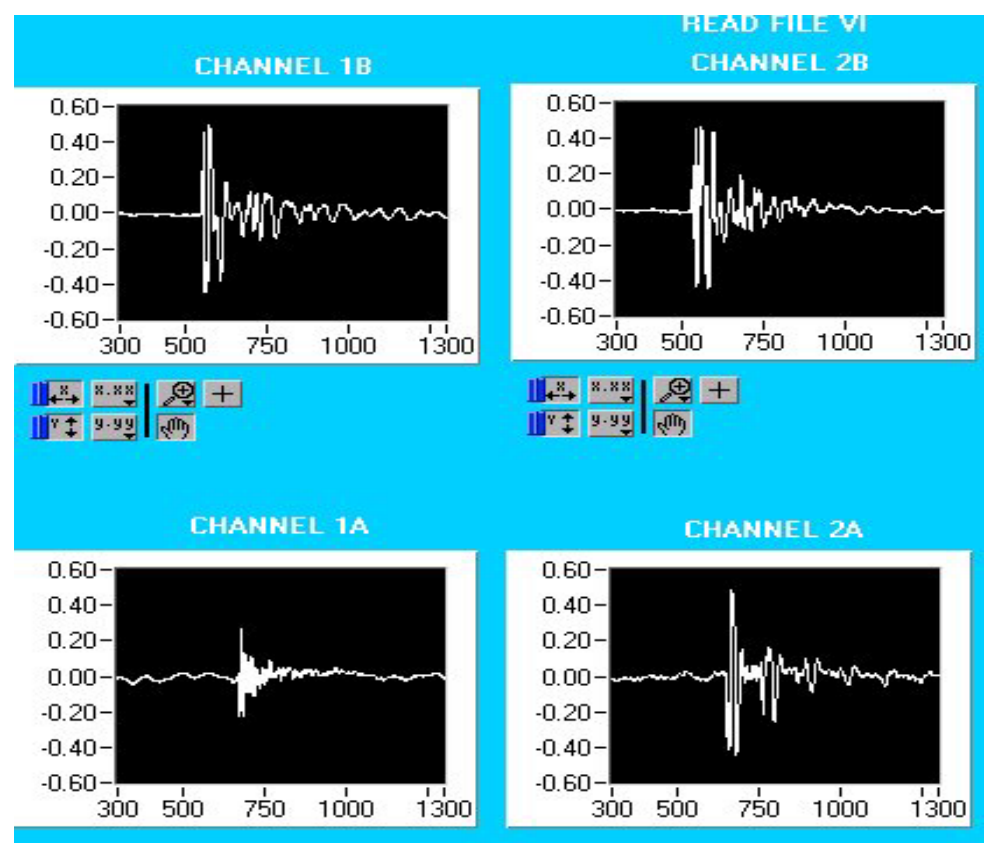

Figure 15. Both pairs of hydrophone traces are from tests using a $1 \mathrm{ft}$ long, 2 in. diameter steel tube with a closed top as a suppressor. The suppressor for the top (B) traces has a steel top, while that for the bottom (A) traces has a rubber top. Neither suppressor was purged. The suppressors were between channels 1 and 2. Both are at a depth of about $58 \mathrm{ft}$. Piezoelectric source.

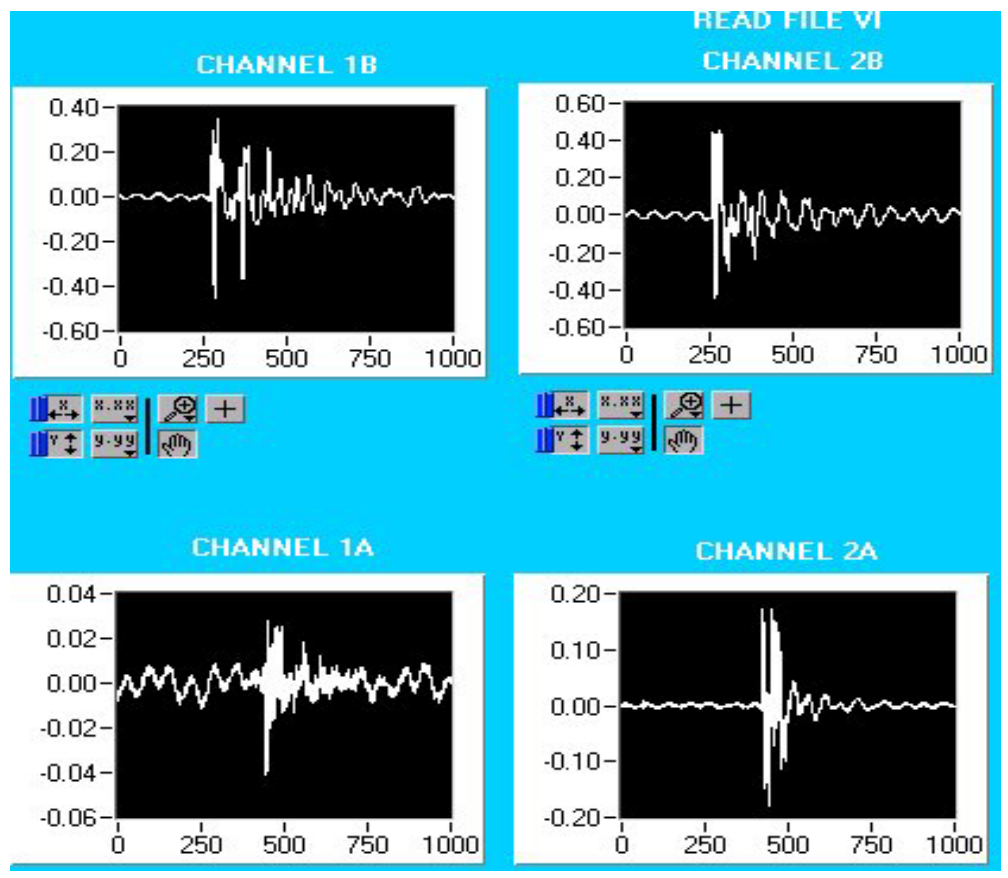

Figure 16. Effects of purging. For the top (B) hydrophone traces, the suppressor was not purged; for the bottom (A) traces it was purged. The same gas volume was used, the difference is the length of water connecting the well bore to the gas volume in the unpurged condition. Channel 1 is the bottom hydrophone, channel 2 the top. The steel pipe suppressor with a closed top is between the receivers and the piezoelectric source is above them. 
4.4.1.3 Orientation. Orientation of the suppressor seems to be of little concern, provided there are no associated inertial or stress factors. A gas volume of specific size and pressure communicating via an unstretched, low-impedance membrane of specific area seems to be indifferent to the direction the membrane faces. An INEEL test demonstrated that rubber covered ports on the side of a gas accumulator worked as well as the same area of porting on the top or bottom (Figure 17). However, the performance deteriorated faster with depth with the side-ported suppressor. This may be due to strain factors being different with four small ports versus one large one. These tests were not purged; an equal length of water was in the bottom of the suppressors for both tests.

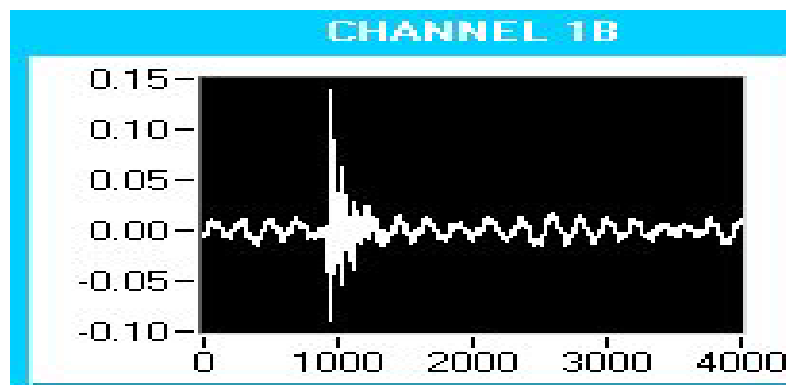

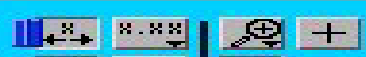

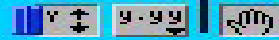

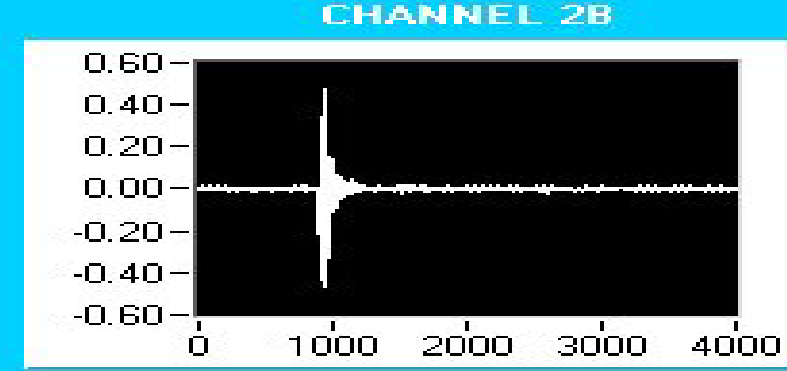

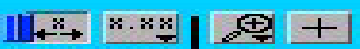
$110 \neq$ y.y
CHANNEL 1A

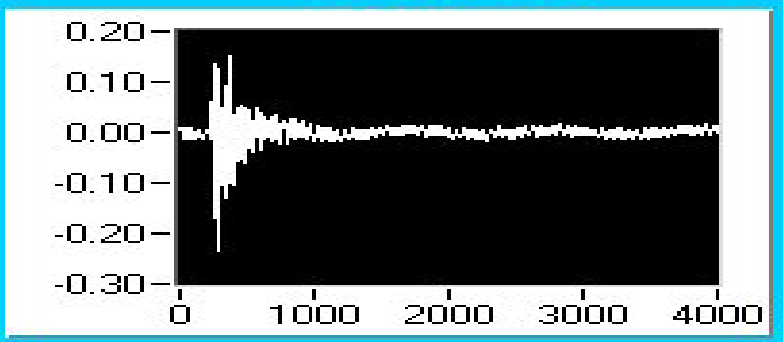

CHANNEL 18

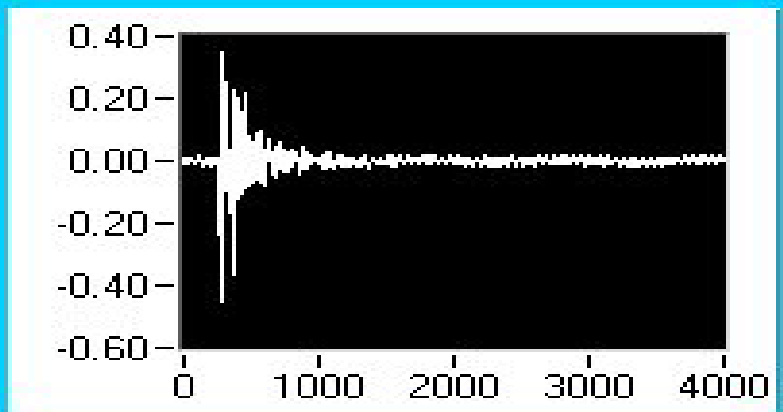



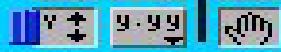

CHANNEL 2A

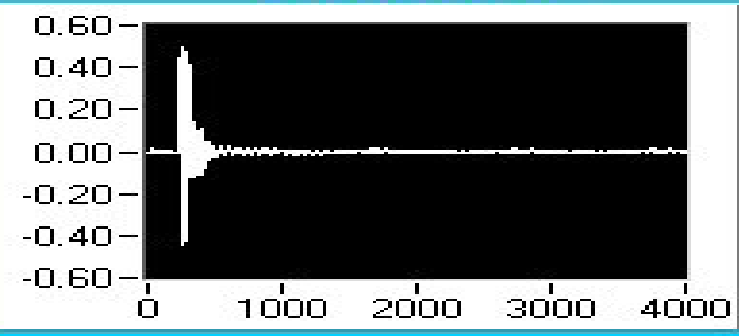

CHANNEL 2B

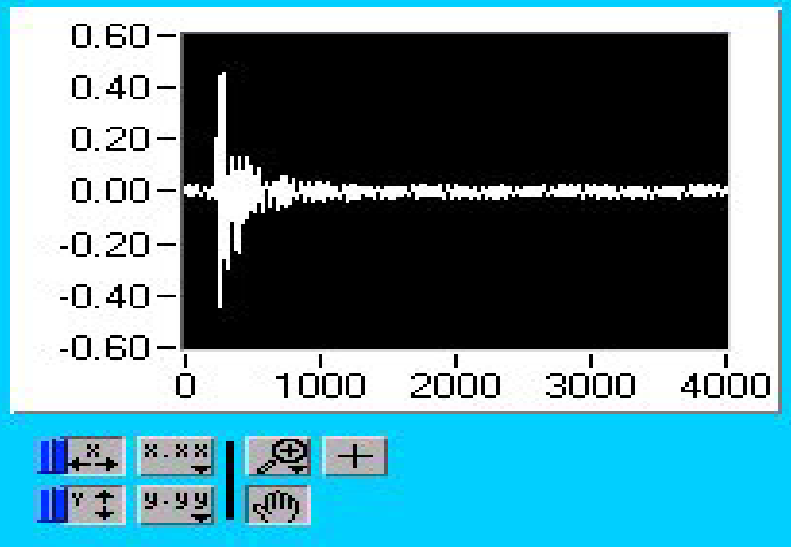

Figure 17. Effect of port location. For the top hydrophone traces the suppressor is a pipe closed with a diaphragm; for middle traces, the suppressor has a steel top and rubber side ports; for bottom traces, the suppressor has a steel top. All are unpurged at $10 \mathrm{ft}$. Channel 1 is the bottom hydrophone, channel 2 the top. The suppressor is between the hydrophones and the piezoelectric source is above them. 


\subsubsection{Seismic Sources and Receivers}

The fluid-borne disturbance is a function of the source type and location. A .22 blank ignited above the water, just inside the casing, is not a good seismic source. It does not even register on geophones just outside the casing. It does, however, create a strong acoustic signal in the borehole, making it useful for testing bore-deployed, fluid-coupled, wave suppressors. The air/water interface just below the cap presents an abrupt impedance mismatch of increased impedance. The transmission of acoustic energy into the well fluid is poor, frequency-dependent, a function of the air-space geometry, and a function of the well and its contents. Quiescent zones resulting from the dominant wavelength admitted and the well (including contents) resonance could be established. Placing compressible air volumes at the bottom of the well changed the response and the location of the quiescent zones. A system could be conceptualized where the source, while emitting its signal to the surroundings, is allowed to transmit only certain frequencies to the borehole fluid. In turn, the resulting TW frequencies could be mitigated by a system of suppressors/reflectors working in harmony with the well to create quiescent zones at the receivers. However, this approach appears to be excessively complex.

The INEEL testing program primarily employed two sources, a piezoelectric source and a .22 blank. Hydrophones were the initial receivers because it was thought that the fluid-borne disturbance was the total problem. In addition, early in the test program, compressible gas volumes were identified as the most useful suppressors. Because of this, the tests evolved around concepts that employed compressible volumes that suppressed the acoustic disturbance in the fluid as registered by the hydrophones. When it was determined that the whole well (water casing and cementing) was involved, other test methods were employed. With the piezoelectric and explosive sources, tests covered a range of suppressor efficiencies. The simple, and very flexible, bladders and diaphragm-occluded chambers proved very effective at removing the piezoelectric source's higher frequency signals from the bore fluid. Real-time comparisons demonstrated that while a significant signal was present, as measured by a hydrophone between source and suppressor, a suppressor could render the signal undetectable as measured by a second hydrophone on the other side of the suppressor. Using the cap source, which produces lower frequencies, poor universal suppression occurred. Subsequent testing, however, noted that specific positioning of components could create quiescent zones offering notable reductions of signature amplitude. The quiescent zones were studied in more detail, but due to the limited well depth, empirical relationships could not be developed to qualify the theory.

As whole-well TW suppressors were tested, we began using geophones to evaluate the performance of suppressors on the casing-borne components of the wave. The first observation was that even large amplitude fluid-borne signals were not detectable with the casing-mounted geophones. These geophones are attached to the outside of the well casing and the casing and the geophones are fully cemented in. These geophones will most assuredly detect the presence of seismic signals in this region. Weight-drop tests demonstrated the complete function of these instruments, with comparable signal received by either a geophone or hydrophone inside the well. During the SWSI tests, only a subsurface combustion seismic source (INEEL design) produced sufficient water-borne signal strength to be detectable by the casing geophones.

Therefore, if strong water-borne signals exist that disturb SWSI techniques but do not also affect external geophones, then the INEEL tests of water-borne (only) signals are relevant. Consequently, our tests results are only limited in field applicability by the shallow well depth.

If a casing-mounted instrument is not disturbed by a TW, it is only the fluid disturbance that creates the problem, even for geophones. Based on this observation, INEEL resumed tests to examine the response of geophones to the effects of a fluid-borne disturbance with and without suppression. Tests indicated that clamping efficiency improves a geophone's ability to resist bore fluid disturbances 
(Figures 18 and 19). ${ }^{a}$ This is not surprising. However, we observed that a suppressor effectively mitigates the disturbance to a geophone, even when it provides little suppression to the signal sensed by hydrophones. It is speculated that the clamped geophone modules used were most disturbed by frequencies in the 40 to $60 \mathrm{~Hz}$ range, and the suppressor filtered out the 40 to $100 \mathrm{~Hz}$ signal. The hydrophones were receiving unsuppressed signals in the $38 \mathrm{~Hz}$ range. One indication contrary to this speculation is that while the suppressor was effective on the $1000 \mathrm{~Hz}$ piezo signal, as received on the hydrophone, it was not effective on the piezo signals received by a geophone (Figure 20). ${ }^{b}$

Casing-transmitted TW disturbance was not totally ignored. INEEL tests were performed using a weight drop source. This source presents a strong signal recorded by both external casing-mounted geophones as well as internal geophones and hydrophones (Figure 21). A suppressor, again using accumulation as the signal absorber, had little or no effect on the recorded signal (Figure 22). This test is likely inconclusive due to the inability to discern a TW from the direct arrival in the shallow well. It would be nice to believe that the signals reflecting back from artifacts could be transmitted into the bore and received without abatement or confusion, but even in cross-well surveys bore-holes in the survey field resonate with TW energy., ${ }^{9,17}$

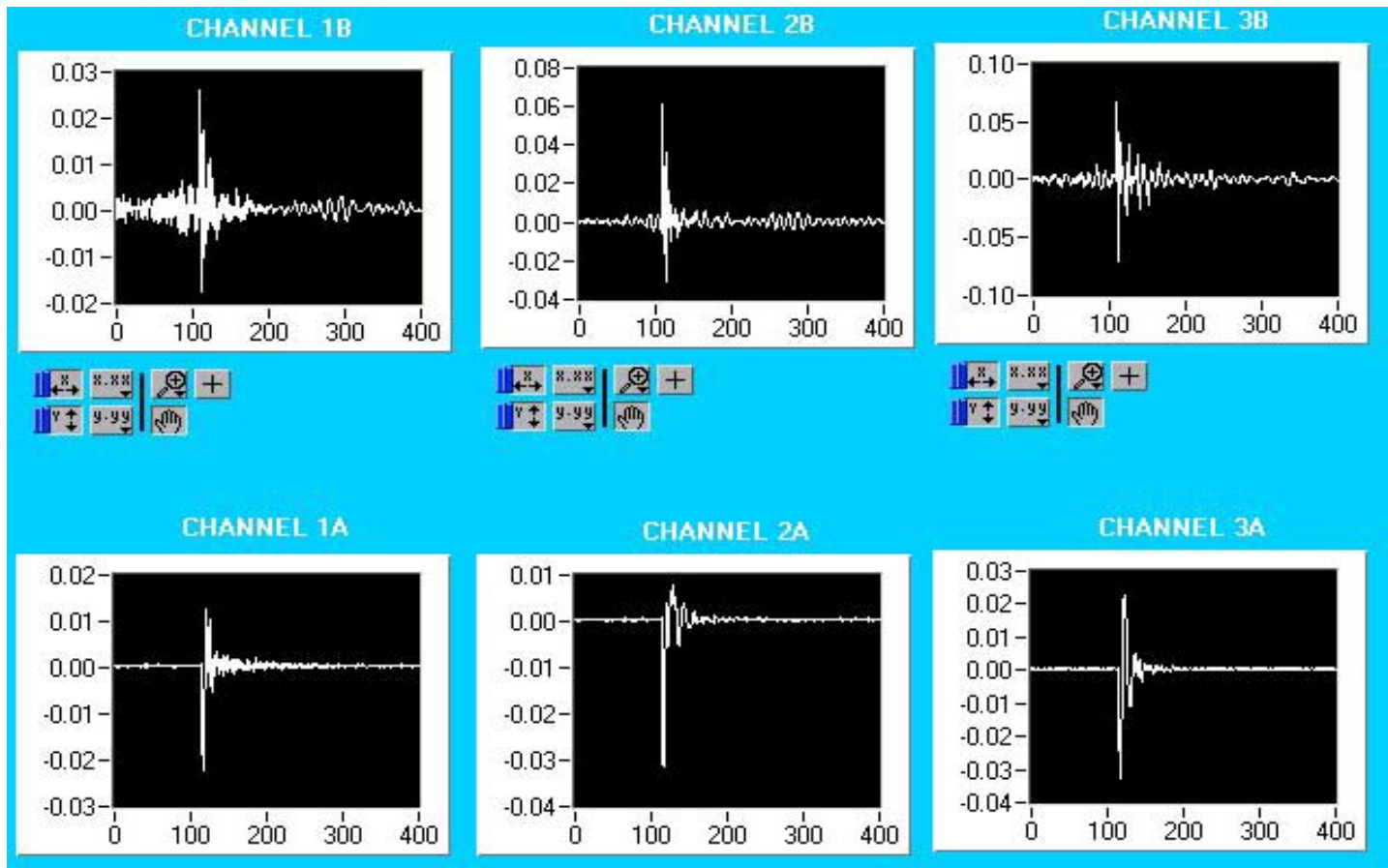

Figure 18. Tri-axial recordings are x',y',z of (top) an unclamped wireline geophone module with no suppressor and of (bottom) internally clamped wireline geophone module with no suppressor. (Not real time) Explosive source.

a. Geophone tests cannot be real time with INEEL equipment.

b. Piezoelectric source used at the INEEL provided poor repeatability. Repeated tests, however, seemed to confirm the observations noted. 


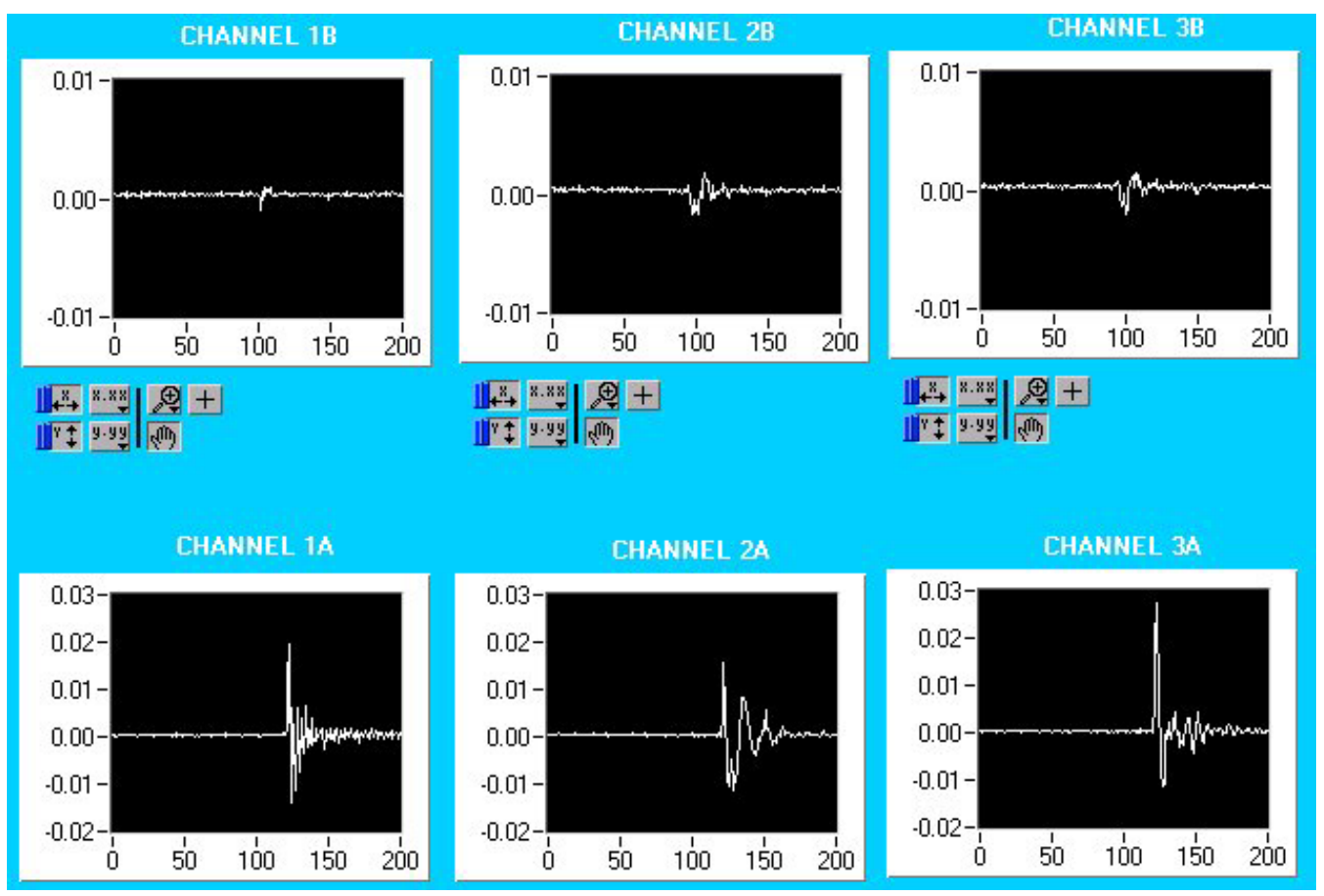

Figure 19. Tri-axial recordings are $x^{\prime}, y^{\prime}, z$ of (top) a clamped wireline geophone module with suppressor between the module and the source and of (bottom) internally-clamped wireline geophone module without suppressor. (Not real time) Explosive source.

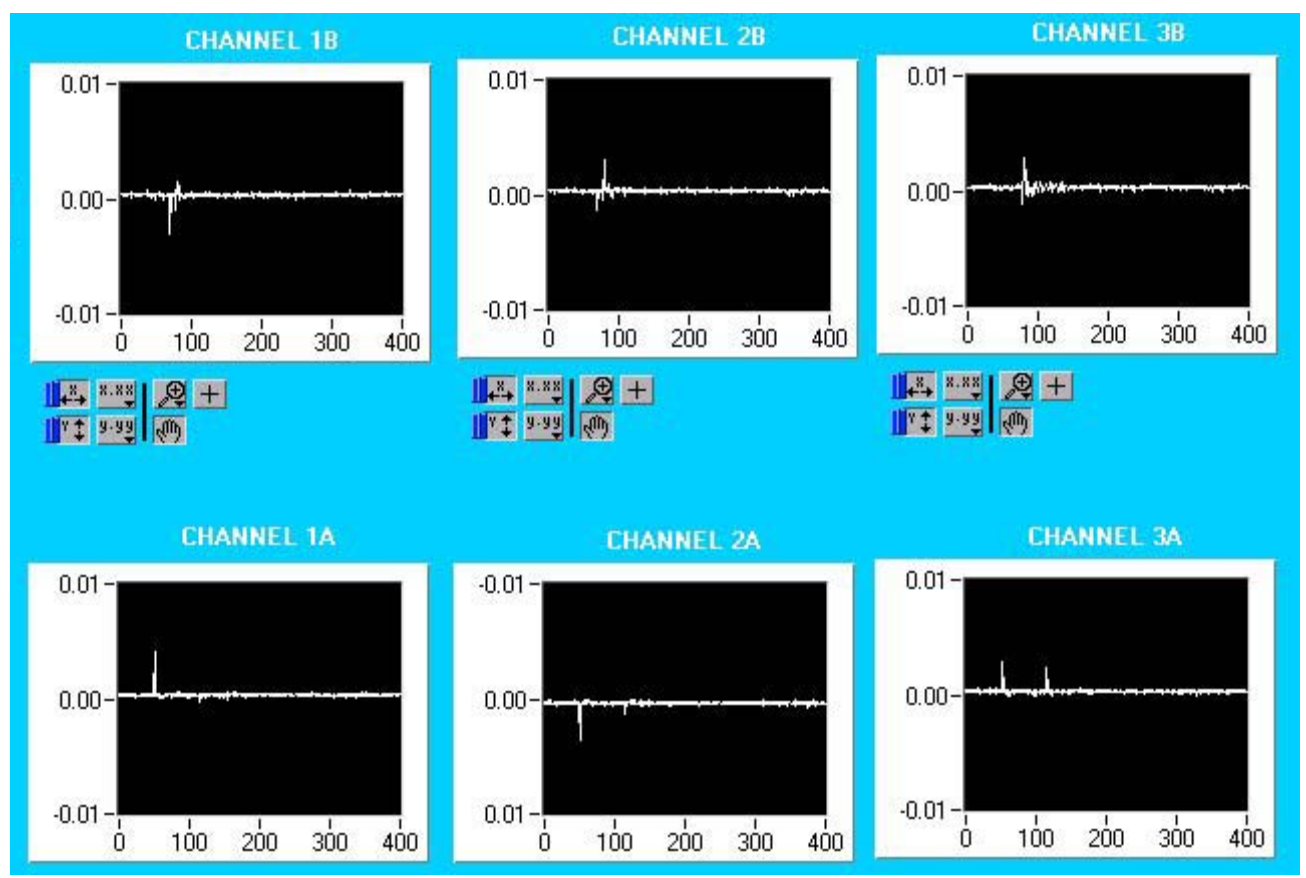

Figure 20. Tri-axial recordings are $x^{\prime}, y^{\prime}, z$ of (top) a clamped wireline geophone module with no suppressor and of (bottom) internally clamped wireline geophone module with a suppressor above the module and below the source. (Not real time) Piezo source. 


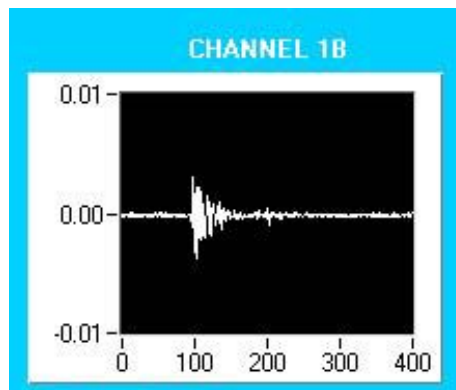

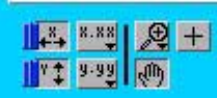
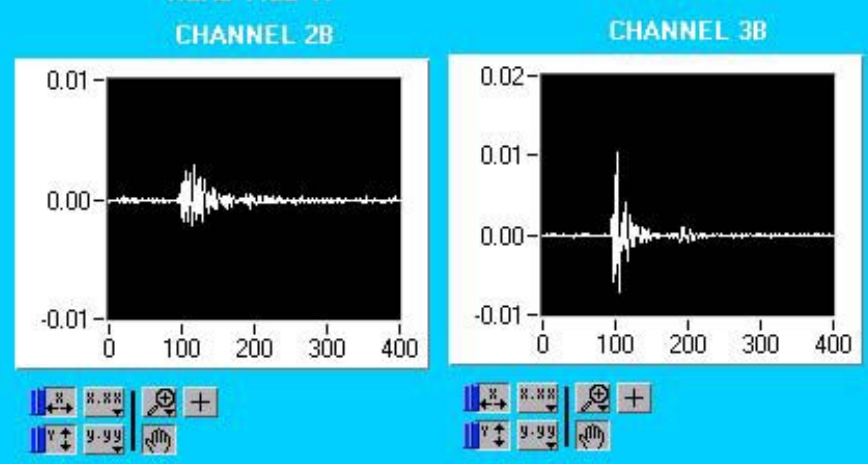

CHANNEL 1 A

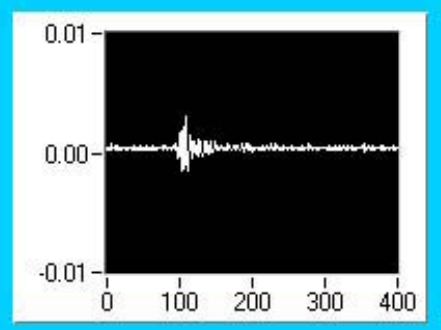

CHANNEL 2A

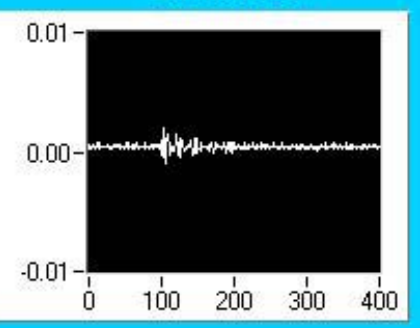

CHANNEL 3A

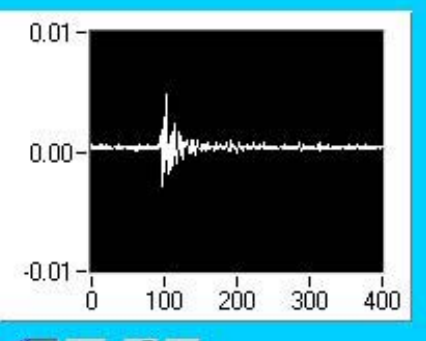

Figure 21. Geophone receivers. The x,y,z, traces are signals from (top) geophones mounted externally on the well casing and from (bottom) an internal, clamped geophone module. Weight-drop source and no suppressor.

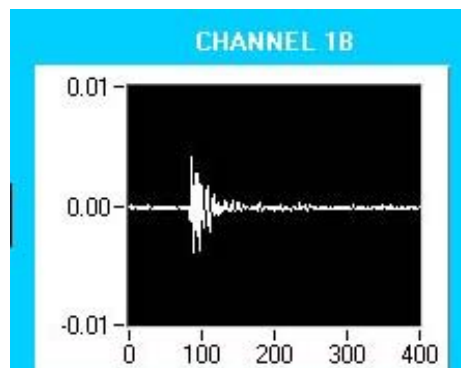

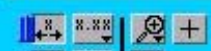

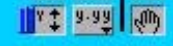

CHANNEL 1A

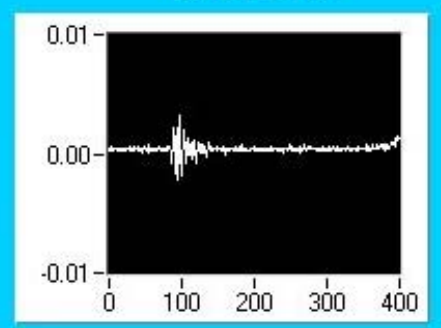

CHANNEL 2B

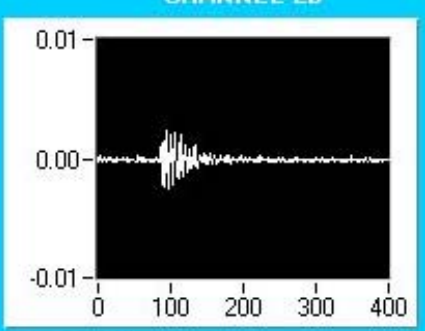

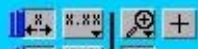

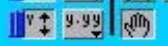
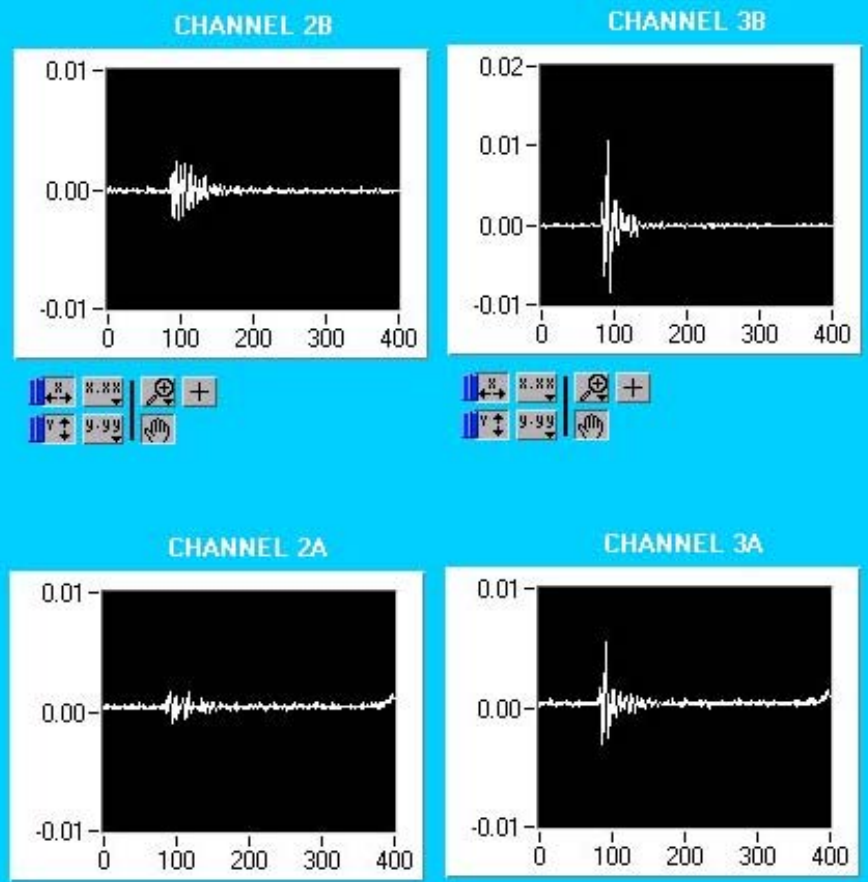

\section{CHANNEL 3A}

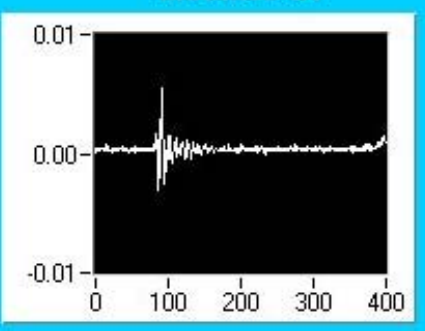

Figure 22. Suppressor test with weight-drop source. Tri-axial recordings are $x, y, z$ of (top) a casing/cemented fixed geophone ("reference") and of (bottom) an internally-clamped wireline geophone module. 


\section{CONCLUSIONS}

Suppressing tube waves is not a trivial task. A source for single well seismic surveys that powerfully transmits energy out of the well (and the surrounding media) cannot avoid putting energy into the well, which will act as a waveguide. The tube waves, then, will resonate as a response to the source spectrum and the physical properties of the well. The fluid-borne portion may be controllable, but it is unlikely that disturbances in the casing and cementing can be modified, especially in any controlled or predicable manner. Consequently, the primary objective should be to minimize a fluid-borne disturbance.

Three elements of a SWSI system can be controlled - the source, the suppression method, and the receivers. We believe that the fluid-borne tube wave is most problematic with monopole sources. Using a dipole source that radiates horizontally in a radial pattern could sufficiently minimize fluid disturbances, but casing-borne TW would still be unmitigated. On the other hand, casing-borne disturbances are also the manifestation of the returning (desired) signal! Consequently, reducing the wave energy is uniquely the desired effect of TW suppression efforts, and this is possible.

The fluid-borne disturbance can be suppressed to some degree by using a damped compressible gas volume to isolate the receivers from the source's signal that is axially transmitted through the borehole fluid. The effectiveness of such systems is a function of the suppression device itself (its impedance, internal damping, accumulation volume, and stiffness), the source, the receivers, and the well and its proximal environment.

The gas volume should be as large as can be facilitated in a low differential soft containment, with damped fluid communication replicating the impedance of the borehole. The gas volume creation is a challenge it but can be done. Contemporary deployments either incorporate a compressed gas system or use a high-pressure gas system at the surface to supply the gas volume through an umbilical. An INEEL design improvement allows the borehole fluid to displace and compress the under-pressured gas into the suppressor to accommodate greater depth. Nevertheless, the inconveniences and hazards associated with compressed gas are still present.

Suppression devices presenting minimal inertia, low or no static strain energy, and low impedance best admit acoustic energy. Once admitted, the energy is best dissipated (at least by passive devices) by conversion to heat through irreversible compression of gas and viscous damping. Viscous damping results from impedance-matched fluid moving significant distances due to a low bulk-modulus zone, such as that offered by compressible gases. Although increased depth will proportionally degrade the ability of a gas to absorb energy, increasing the volume will proportionally restore effectiveness. Testing found that suppression is a function of both area and volume and that diaphragms are more effective than bladders for the same volume and face area. It is speculated that the strain imposed on the face surfaces of a bladder inhibits its response to small pressure disturbances. This increased strain can be caused by the differential pressure imposed on the walls and restrained by the faces, or because the bladder may be restraining higher differential inflation pressure. This, in turn, implies that tall devices will be less effective than the same volume in multiple short devices. INEEL tests indicate that deploying more suppressors on one string offers diminishing improvements. Thin diaphragms are more effective than very thick ones. This is likely because the impedance of rubber is slightly higher than that of water and the "stiffness" of a sheet is cubic to thickness.

It is possible to find quiescent zones, but concepts employing reflection/tuning for receiver isolation will also have to include an energy absorption provision to accommodate universal application. It is expected that once a suitable energy absorption technique is employed, reflection/tuning will become less necessary. 
INEEL tests show that hydrophones can tolerate TWs with the right suppressor, geometry, and source spectrum. For clamped geophones, the effects of the fluid-borne signal can be mitigated but the casing-borne signal is omnipresent and indistinguishable from the return signals, except for first-arrival information. Given the indeterminate variability of borehole discontinuities, casing and cementing, casing reflections may not be tolerable even with suppression. Using the best source, i.e. the one that causes the least casing/cementing disturbance for overall power, and clamped geophones will likely provide the best results with or without suppression. Nevertheless, geophone system operation can be enhanced by suppression of bore fluid disturbances, if they are present. 


\section{REFERENCES}

1. West, P. B., J. R. Fincke, D. M. Weinberg, and J. H. Cole, 2001, Clamping Systems for Large Downhole Seismic Sensor Arrays, Idaho National Engineering and Environmental Laboratory Report INEEL/EXT-01-00754.

2. Turpening, Roger, 1996, personal communication.

3. Howlett, Don, 1998, personal communication.

4. Herman, G. C., P. A. Milligan, Q. Dong, and J. W. Rector, 2000, "Analysis and Removal of Multiply Scattered Tube Waves," Geophysics, Vol. 65, No. 3, pp. 745-754.

5. Cole, J. H. , November 23, 2000, Single-Well Seismic Imaging And Tube Waves Final Report, Department of Mechanical Engineering, University of Arkansas, Fayetteville, Arkansas.

6. Paulsson, Bjorn N. P., May 19, 1999, Seismic Imaging Consortium annual meeting, New Orleans.

7. Daley, T. M., E. L. Majer, and R. Gritto, 2000, Single Well Seismic Imaging - Status Report, Lawrence Berkeley National Laboratory Report Number 45342.

8. Daley, T. M, and R. Gritto, April 16, 2001, Borehole Seismic System Tests at Richmond Field Station, Lawrence Berkeley National Laboratory Report Number 49015.

9. H. Wang, G. H. Priestman, S. B. M. Beck, and R. F. Boucher, 2000, "Measurement and Simulation of Pressure Wave Suppression in Upward Air-Water Bubbly Flow," Heat and Fluid Flow, 21.

10. Berry, J. E. and A. J. D. Straus, 1976, “Acoustical Logging Apparatus Having Signal Delay Means,” U.S. Patent No. 3,982,606.

11. Curran, J. W., 1986, “Acoustic Logging in Low Velocity Formations,” U.S. Patent No. 4,611,685.

12. Chelminski, S. V., 1989, "Tube-Wave Attenuation Method, System and Apparatus for Use with Impulsive Seismic Energy Source in Liquid-Containing Wells,” U.S. Patent No. 4,858,718.

13. Fairborn, J. W., 1991, “Attenuation of Borehole Tube-Waves,” U.S. Patent No. 5,005,666.

14. Balogh, W. T. and J. T. O’Brien, 1992, “Tubewave Damper Probe for Seismic Applications,” U.S. Patent No. 5,171,943.

15. Daley, T. M., E. L. Majer, R. Gritto, and P. B. West, February 4, 2002, Tube-wave Suppression in Single Well Seismic Acquisition, Lawrence Berkeley National Laboratory Report Number 49769.

16. Kinsler, L. E., and A. R. Frey, Fundamentals of Acoustics, 2nd ed., Wiley, equation 6.37 (p. 138).

17. Crocker, S., and R. C. King, Piping Handbook, 5th ed, McGraw Hill. 